Sharif University of Technology
Scientia Iranica
SCIENTIA
IRAN ICA
http://scientiairanica.sharif.edu

\title{
Controlling the deflection of long beams using different patterns of pre-tensioning cables
}

\author{
N. Fanaie*, F. Partovi, and S. Safaei Faegh \\ Department of Civil Engineering, K. N. Toosi University of Technology, Tehran, Iran.
}

Received 24 July 2018; received in revised form 3 April 2019; accepted 8 June 2019

\section{KEYWORDS}

Deflection;

Steel beam;

Cable;

Pre-tensioning;

Least work;

Virtual work.

\begin{abstract}
Despite appropriate design of beams under bending and shear, the deflection of long steel beams usually exceeds the allowable range, and therefore the structural designers encounter challenges in this regard. Considering significant features of the cables, namely, low weight, small cross section, and high tensile strength, they are used in this research so as to control the deflection of beams, rather than increasing their heights, and obtain acceptable responses. In this study, for the first time, theoretical relations are developed to calculate the increase in pre-tensioning force of cables under external loading based on the method of least work as well as the deflection of steel beams with different support conditions and cable patterns based on the virtual work method. To verify the theoretical relations, the steel beams are modeled in the finite element Abaqus software. The obtained results show that the theoretical relations can appropriately predict the deflection of beams with different support conditions and cable patterns. In this study, simply supported as well as fixed supported beams are pre-stressed with V-shaped and modified V-shaped patterns of the cable. According to the obtained results, the modified V-shaped pattern of the cable is more efficient than V-shaped pattern.
\end{abstract}

(C) 2021 Sharif University of Technology. All rights reserved.

\section{Introduction}

As important components of a structure, cables are materials which can tolerate tensile force, and generally increase the stiffness and bearing capacity of a structure [1]. Nowadays, cables are increasingly used in structures. Hou and Tagawa applied cablecylinder bracing in the seismic retrofitting of steel flexural frames. From their view point, through this retrofitting method, the lateral strength of the

\footnotetext{
*. Corresponding author. Tel.: +9821 88779623 E-mail addresses: fanaie@kntu.ac.ir (N. Fanaie); he.partovi@gmail.com (F.Partovi); safaei.faegh.s@gmail.com (S. Safaei Faegh)
}

doi: $10.24200 /$ sci.2019.51479.2205 storey augments without decreasing the ductility of flexural frame [2]. Fanaie et al. presented theoretical relations for the cable-cylinder bracing system using a rigid cylinder like steel cylinder. They verified the results by finite element Abaqus software [3]. They also studied seismic behavior of steel flexural frames strengthened with cable-cylinder bracing and obtained reasonable results [4]. Giaccu investigated the nonlinear dynamic behavior of pre-tensioned-cable crossbraced structures in the presence of slackening in the braces. They concluded there is a direct correlation between equivalent frequency and slackening in the braces [5].

Pre-tensioning of steel beams through high strength cables is one of the most efficient methods so as to decrease the required steel and increase their bearing capacity. Pre-tensioning technique has 
been primarily used in reinforced concrete structures. Brunesi et al. evaluated the shear capacity of precastpre-stressed Hollow Core Slabs (HCS) numerically and experimentally. They concluded that peak shear stress is localized at the bottom side of the cross-section, rather than at the level of the centroid [6]. AlNegheimish et al. did an experimental study on the long term deflection of pre-stressed HCS. Their results were compared with the predictions of the effective modulus approach which considers the creep and shrinkage models prescribed by ACI 209 Committee [7]. for the first time, it was utilized by Dischinger and Magnel in steel beams. Pre-tensioned steel structures are constructed all over the world, especially in America, Russia, and Germany. This fact shows the structural and economic merits of pre-stressed steel beams compared to nonpre-stressed ones. The pre-tensioning technique is appropriate to construct new structures as well as strengthening the existing ones [8].

Some researchers have studied pre-stressed concrete and composite beams using steel cable. Le et al. evaluated experimentally the application of both unbonded Carbon Fibre Reinforced Polymer (CFRP) tendons and steel tendons on precast $\mathrm{T}$-section segmental concrete. They concluded CFRP tendons can show good performance in replacement of steel tendons and the beams achieve both good strength and ductility capacity [9]. Pisani analysed the simply supported concrete beam externally pre-stressed under sustained loads and introduced two numerical methods able to describe the time evolution of both the stress distribution and the displacements of a simply supported concrete beam externally pre-stressed and presented an example to verify the precision of the methods [10]. Lou et al. numerically studied the flexural response of continuous externally fiber reinforced polymer prestressed concrete beams having various linearly transformed cable profiles. They observed that the cable shift by linear transformation does not affect the basic performance at all stages of loading up to failure and that the secondary moments vary linearly with the cable shift [11]. Ayyub et al. assessed pre-stressed steelconcrete composite beams experimentally as well as analytically using steel cable in the regions of positive and negative bending moments. They concluded that pre-tensioning increases the ultimate strength $[12,13]$. Nie et al. presented theoretical relations to calculate the deflection as well as yield and ultimate moments of simply supported pre-stressed steel-concrete composite beam considering the slip effect. They verified the suggested formulas with the experimental results [14]. Zhou et al. presented the experimental study as well as numerical modeling of pre-stressed composite beams subjected to fire and positive moment. They observed that the fire resistance of composite beams pre-stressed with external tendons was highly influenced by the stress in the cable strands [15]. Pre- stressed steel beams equipped with steel cables have been investigated by some researchers. Troitsky evaluated the behavior of pre-stressed steel beam using cables, and observed the increase in the stiffness and decrease in the deformation of the beam [8]. Belletti and Gasperi studied the behavior of pre-stressed simply supported steel I-shaped beams by tendons with focusing on two parameters, namely, the number of deviators and the value of pre-stressing force [16]. Park et al. analytically and experimentally evaluated the flexural behavior of steel I-beam pre-stressed with externally unbonded tendons. They figured out considerable increase in the yielding and ultimate bearing capacity of steel Ibeam [17]. Kambal et al. derived a finite-element formulation to investigate the effectiveness of applying the pre-stressing technique with respect to the flexural behavior of a simply supported steel box girder and they verified it by experimental results [18]. Zhang examined the analytical solutions of the symmetric and antisymmetric elastic lateral torsional buckling of prestressed steel I-beams with rectilinear tendons, under equal end moments [19]. Thai et al. have studied different types of cable net and optimized their volume as an objective function, considering the allowable stress and maximum displacement as optimization constraints. They applied the appropriate pretension forces to the cable nets to reduce the displacement of structure and obtain the optimal volume as well. Moreover, they concluded that the pretension forces play a significant role on obtaining the optimal volume when the displacement constraint is relatively small or the allowable stress is relatively large [20].

Since controlling the deflection of beams, especially long beams, confronts the structural designers with challenge, this research focuses on the deflection of steel beams with various support conditions along with different patterns of cable. The increase of pretensioning force of steel cable subjected to external loading is determined using method of least work. Then, the method of virtual work is applied to develop the deflection relations of steel beams equipped with cable. In order to validate the obtained deflection relations, the results of theoretical relations are compared with those of finite element models of the beams.

\section{Pre-tensioning symmetric I-shaped steel beams with steel cable}

Symmetric I-shaped steel beams have been considered with different support conditions, namely, simply supported, and fixed supported beams. As shown in Figure 1 , pre-stressed cables with different patterns have been used in both sides of beam web, and subjected to external loading. As observed in the figure, regarding the $\mathrm{V}$-shaped pattern, the cable is fixed at both ends 


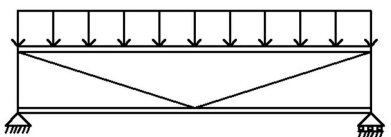

(a)

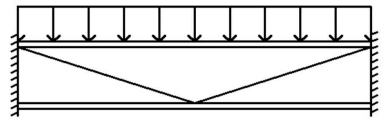

(c)

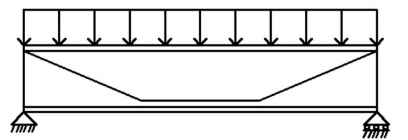

(b)

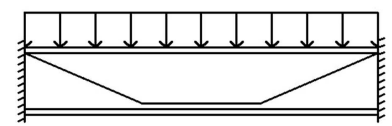

(d)
Figure 1. Pre-stressed symmetric I-shaped steel beams with steel cable under external loading: (a) Simply supported beam along with V-shaped cable pattern, (b) simply supported beam along with modified V-shaped cable pattern, (c) fixed supported beam along with V-shaped cable pattern, and (d) fixed supported beam along with modified V-shaped cable pattern.

to the top flange of the beam in both sides of the web. Then, in the middle of the beam, it passes through the deviator on the bottom flange creating a pattern with two inclined cables. Moreover, in the modified Vshaped pattern, the cable is fixed at both ends to the top flange of the beam in both sides of the web, and then it passes through two deviators on the bottom flange producing a pattern with one horizontal cable in the middle and two inclined ones in each side.

The following assumptions are taken into account to analyze pre-stressed symmetric I-shaped steel beams with steel cable:

1. The materials of steel beam and cable are linearly elastic;

2. The deformations are small;

3. Shear deformation is not considered;

4. The friction loss in the region of cable deformation and the relaxation of steel cable are ignored;

5. The steel beam has the hot rolled section; therefore, it is compact.

\section{Increase of pre-tensioning force of the steel cable in a beam under external loading}

The cable length increased by $\Delta L$, and its pretensioning force, $F_{p t}$, increased by $\Delta F$, under uniform distributed loading. As the structure is statically indeterminate, the static equilibrium equations are not enough to calculate $\Delta F$. The increase of the force in the cable can be calculated using the method of least work.

The total strain energy of the beam caused by its bending moment and axial force in different support conditions and various patterns of cable as well as the strain energy of the cable owing to its axial force are determined to calculate the increase in pretensioning force of the cable through the method of least work. Then, the relation of total strain energy is differentiated with respect to $\Delta F$ and the result is equated to zero to obtain the relation to increase the pre-tensioning force of the cable $(\Delta F)$.

\subsection{The simply supported beam along with the $V$-shaped pattern of the cable}

Regarding the simply supported beam with V-shaped cable pattern, as shown in Figure 2, the increase in pre-tensioning force of the steel cable is equal to $\Delta F$. Therefore, axial force of the beam is equal to $\Delta F \cos \theta$. Considering the symmetry of structure and loading (Figure 2), the bending moment diagram plotted for right half of the beam is exactly the same as that of its left one. Hence, the strain energy caused by bending moment can be obtained for half of the beam and then it is duplicated to calculate the bending strain energy of the whole beam. In what follows, the bending moment for simply supported beam along with $\mathrm{V}$-shaped pattern of cable is obtained under uniform distributed loading for half of the beam to calculate the strain energy caused by bending moment:

For $0 \leq x \leq \frac{l_{b}}{2}$ range:

$$
M(x)=-\Delta F \sin \theta x+\Delta F \cos \theta y_{0}-\frac{q x^{2}}{2}+\frac{q l_{b} x}{2} .
$$

Considering the symmetry of structure and loading, the total strain energy equation is written as follows:

$$
\begin{aligned}
& U=2 \times \frac{1}{2(E I)_{b}} \int_{0}^{\frac{l_{b}}{2}} \\
& \left(-\Delta F \sin \theta x+\Delta F \cos \theta y_{0}-\frac{q x^{2}}{2}+\frac{q l_{b} x}{2}\right)^{2} d x \\
& +2 \times \frac{\Delta F^{2} l_{c}}{2(A E)_{c}}+\frac{(\Delta F \cos \theta)^{2} l_{b}}{2(A E)_{b}}=\frac{1}{(E I)_{b}} \\
& \left\{\begin{array}{l}
\frac{q^{2} l_{b}{ }^{5}}{240}+\frac{\Delta F^{2} l_{b}{ }^{3} \sin ^{2} \theta}{24}+\frac{\Delta F^{2} l_{b} y_{0}{ }^{2} \cos ^{2} \theta}{2} \\
-\frac{\Delta F^{2} l_{b}{ }^{2} y_{0} \sin \theta \cos \theta}{4}-\frac{5 q \Delta F l_{b}{ }^{4} \sin \theta}{192}+\frac{q \Delta F l_{b}{ }^{3} y_{0} \cos \theta}{12}
\end{array}\right\} \\
& +\frac{\Delta F^{2} l_{c}}{(A E)_{c}}+\frac{\Delta F^{2} l_{b} \cos ^{2} \theta}{2(A E)_{b}} .
\end{aligned}
$$

In order to calculate the increase in pre-tensioning force

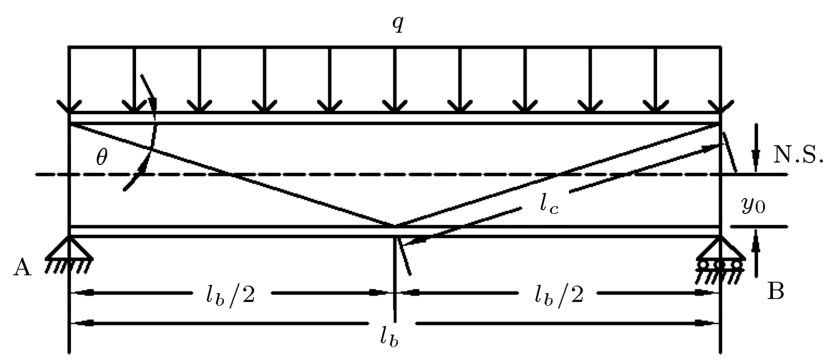

Figure 2. Simply supported beam with V-shaped pattern of cable. 
of the cable $(\Delta F)$ through the method of least work, the relation of whole strain energy is differentiated with respect to $\Delta F$ and the obtained result is equated to zero:

$$
\frac{\partial U}{\partial(\Delta F)}=0
$$

The relation for calculating the increase of pretensioning force of the cable $(\Delta F)$ is obtained by Eq. (4) as shown in Box I, where, $q$ is the intensity of uniform distributed load; $l_{b}$ and $l_{c}$ are the lengths of beam and inclined cable, respectively; $A_{b}$ and $A_{c}$ are the cross sections of the beam and cable at both sides of the web, respectively; $E_{b}$ and $E_{c}$ are modulus of elasticity of the beam and cable, respectively; $I_{b}$ is the moment of inertia of steel section; $y_{0}$ is the distance of neutral surface to the connection point of steel cable to the beam flanges (half of the height of beam web); and $\theta$ is the angle between the inclined cable and horizontal axis.

Considering Eq. (4), if the angle between the inclined cable and horizontal axis $(\theta$, as shown in Figure 2 ) approaches to zero, the increase of pre-tensioning force for a straight cable pattern would be obtained as follows. It is noticeable that in this special state, considering Figure $2, l_{c}$ can be replaced by $l_{b} / 2$ in Eq. (4).

$$
\Delta F=\frac{q l_{b}^{2} y_{0}}{12 I_{b}\left(\frac{y_{0}^{2}}{I_{b}}+\frac{E_{b}}{(A E)_{c}}+\frac{1}{A_{b}}\right)} .
$$

The same result was obtained by Hoadley as well as Belenya using the total strain energy of the beam $[21,22]$.

\subsection{The simply supported beam along with the modified $V$-shaped pattern of cable}

Concerning the simply supported beam with the modified V-shaped pattern of cable, as shown in Figure 3, the force of horizontal cable should be equal to the horizontal component of the force of inclined cable to keep the bending moment continuous in the slope change region of cable. Therefore, if the increase in pre-tensioning force of steel cable is assumed as $\Delta F$ in the slope parts, then it will be equal to $\Delta F \cos \theta$ in the horizontal part; hence, the axial force of the beam is equal to $\Delta F \cos \theta$.

Considering the symmetry of structure and loading (Figure 3 ), the bending moment diagram plotted

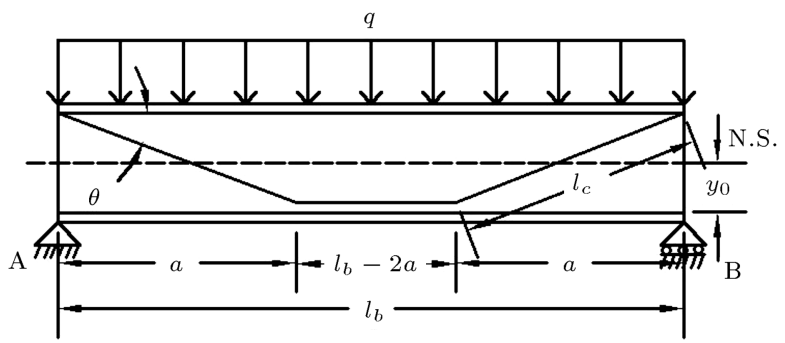

Figure 3. Simply supported beam along with the modified V-shaped pattern of cable.

for right half of the beam is exactly the same as that of its left one. Therefore, the strain energy caused by bending moment can be determined for half of the beam and duplicated to calculate the bending strain energy for the whole beam. In what follows, bending moment is obtained for simply supported beam along with the modified $\mathrm{V}$-shaped pattern of cable under uniform distributed loading for half of the beam to calculate the strain energy caused by bending moment:

For $0 \leq x \leq a$ range:

$$
M_{1}(x)=-\Delta F \sin \theta x+\Delta F \cos \theta y_{0}-\frac{q x^{2}}{2}+\frac{q l_{b} x}{2} .
$$

For $a \leq x \leq \frac{l_{b}}{2}$ range:

$$
M_{2}(x)=-\Delta F \cos \theta y_{0}-\frac{q x^{2}}{2}+\frac{q l_{b} x}{2} .
$$

Considering the symmetry of structure and loading, the total strain energy equation is written in Eq. (8) as shown in Box II. The increase in pre-tensioning force of cable $(\Delta F)$ calculated through the method of least work is defined by Eq. (9) as shown in Box III, where, $a$ is the distance between the support and slope change region of the cable (horizontal projection of inclined cable).

Considering Eq. (9), if the length of horizontal cable $\left(l_{b}-2 a\right.$, as shown in Figure 3$)$ approaches to zero, Eq. (4) is obtained for specific status of the V-shaped pattern of cable.

\subsection{The fixed supported beam with the $V$-shaped pattern of cable}

In the fixed supported beam along with the V-shaped pattern of cable, as shown in Figure 4, the increase of pre-tensioning force of steel cable is equal to $\Delta F$. Therefore, axial force of the beam is equal to $\Delta F \cos \theta$. It should also be mentioned that the fixed supported

$$
\Delta F=\frac{5 q l_{b}{ }^{4} \sin \theta-16 q l_{b}{ }^{3} y_{0} \cos \theta}{16\left(l_{b}{ }^{3} \sin ^{2} \theta+12 l_{b} y_{0}{ }^{2} \cos ^{2} \theta-6 l_{b}{ }^{2} y_{0} \sin \theta \cos \theta+\frac{24(E I)_{b} l_{c}}{(A E)_{c}}+\frac{12 I_{b} l_{b} \cos ^{2} \theta}{A_{b}}\right)}
$$




$$
\begin{aligned}
U=2 \times & \frac{1}{2(E I)_{b}}\left\{\begin{array}{l}
\int_{0}^{a}\left(-\Delta F \sin \theta x+\Delta F \cos \theta y_{0}-\frac{q x^{2}}{2}+\frac{q l_{b} x}{2}\right)^{2} d x \\
+\int_{a}^{\frac{l_{b}}{2}}\left(-\Delta F \cos \theta y_{0}-\frac{q x^{2}}{2}+\frac{q l_{b} x}{2}\right)^{2} d x
\end{array}\right\}+2 \times \frac{\Delta F^{2} l_{c}}{2(A E)_{c}}+\frac{(\Delta F \cos \theta)^{2}\left(l_{b}-2 a\right)}{2(A E)_{c}} \\
& +\frac{(\Delta F \cos \theta)^{2} l_{b}}{2(A E)_{b}}=\frac{1}{(E I)_{b}}\left\{\begin{array}{l}
\frac{q^{2} l_{b}}{240}+\frac{\Delta F^{2} a^{3} \sin ^{2} \theta}{3}+\frac{\Delta F^{2} l_{b} y_{0}{ }^{2} \cos ^{2} \theta}{2}-\Delta F^{2} y_{0} a^{2} \sin \theta \cos \theta+\frac{q \Delta F a^{4} \sin \theta}{4} \\
-\frac{q \Delta l_{b} a^{3} \sin \theta}{3}-\frac{2 q \Delta F y_{0} a^{3} \cos \theta}{3}+q \Delta F l_{b} y_{0} a^{2} \cos \theta-\frac{q \Delta F l_{b} y_{0} \cos \theta}{12}
\end{array}\right\} \\
& +\frac{\Delta F^{2} l_{c}}{(A E)_{c}}+\frac{\Delta F^{2}\left(l_{b}-2 a\right) \cos ^{2} \theta}{2(A E)_{c}}+\frac{\Delta F^{2} l_{b} \cos ^{2} \theta}{2(A E)_{b}} .
\end{aligned}
$$

Box II

$$
\Delta F=\frac{-3 q a^{4} \sin \theta+4 q l_{b} a^{3} \sin \theta+8 q y_{0} a^{3} \cos \theta-12 q l_{b} y_{0} a^{2} \cos \theta+q l_{b}^{3} y_{0} \cos \theta}{4\left(2 a^{3} \sin ^{2} \theta+3 l_{b} y_{0}^{2} \cos ^{2} \theta-6 y_{0} a^{2} \sin \theta \cos \theta+\frac{3(E I)_{b}}{(A E)_{c}}\left[2 l_{c}+\left(l_{b}-2 a\right) \cos ^{2} \theta\right]+\frac{3 I_{b} l_{b} \cos ^{2} \theta}{A_{b}}\right)} .
$$

\section{Box III}

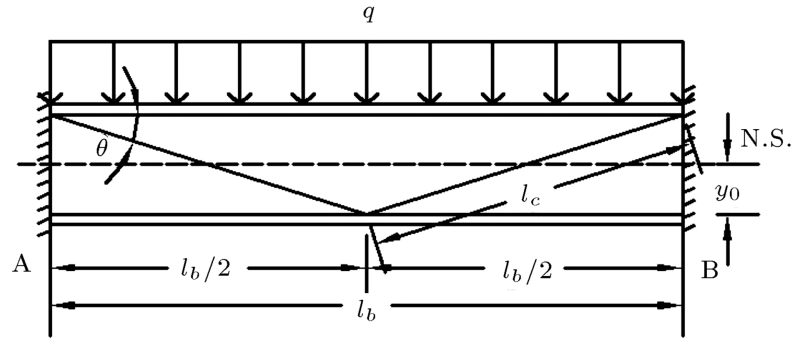

Figure 4. Fixed supported beam along with the V-shaped pattern of cable.

beam along with $\mathrm{V}$-shaped pattern of cable has two degrees of indeterminacy (the increase of pre-tensioning force of the cable, $\Delta F$ and the moment at fixed end, $M)$. To calculate the increase of pre-tensioning force of the cable as well as the moment at fixed end through the method of least work, the relation of total strain energy is differentiated with respect to each of them and the results are equated to zero resulting in the desired relations. Hence, bending moment of fixed supported beam along with the V-shaped pattern of cable under uniform distributed loading is obtained for half of the beam so as to calculate the strain energy caused by bending.

For $0 \leq x \leq \frac{l_{b}}{2}$ range:

$$
M(x)=-\Delta F \sin \theta x+\Delta F \cos \theta y_{0}-\frac{q x^{2}}{2}+\frac{q l_{b} x}{2}-M .
$$

Considering the symmetry of structure and loading, the total strain energy equation is written in Eq. (11) as shown in Box IV. In order to calculate the moment at fixed end $(M)$ through the method of least work, the relation of whole strain energy is differentiated with respect to $M$ and the obtained result is equated to zero:

$$
\frac{\partial U}{\partial M}=0
$$

The calculated bending moment at the fixed end $(M)$ is determined as follows:

$$
\begin{aligned}
U & =2 \times \frac{1}{2(E I)_{b}} \int_{0}^{\frac{l_{b}}{2}}\left(-\Delta F \sin \theta x+\Delta F \cos \theta y_{0}-\frac{q x^{2}}{2}+\frac{q l_{b} x}{2}-M\right)^{2} d x+2 \times \frac{\Delta F^{2} l_{c}}{2(A E)_{c}}+\frac{(\Delta F \cos \theta)^{2} l_{b}}{2(A E)_{b}} \\
& =\frac{1}{(E I)_{b}}\left\{\begin{array}{l}
\frac{q^{2} l_{b}{ }^{5}}{240}+\frac{\Delta F^{2} l_{b}{ }^{3} \sin ^{2} \theta}{24}+\frac{\Delta F^{2} l_{b} y_{0}{ }^{2} \cos ^{2} \theta}{2} \\
-\frac{\Delta F^{2} l_{b}{ }^{2} y_{0} \sin \theta \cos \theta}{4}-\frac{5 q \Delta F l_{b}{ }^{4} \sin \theta}{192}+\frac{q \Delta F l_{b}{ }^{3} y_{0} \cos \theta}{12} \\
+\frac{M \Delta F l_{b}{ }^{2} \sin \theta}{4}-M \Delta F l_{b} y_{0} \cos \theta-\frac{q M l_{b}{ }^{3}}{12}+\frac{M^{2} l_{b}}{2}
\end{array}\right\}+\frac{\Delta F^{2} l_{c}}{(A E)_{c}}+\frac{\Delta F^{2} l_{b} \cos ^{2} \theta}{2(A E)_{b}}
\end{aligned}
$$




$$
M=\frac{q l_{b}^{2}}{12}-\frac{\Delta F l_{b} \sin \theta}{4}+\Delta F y_{0} \cos \theta .
$$

To calculate the increase in pre-tensioning force of cable $(\Delta F)$ through the method of least work, the relation of whole strain energy is differentiated with respect to $\Delta F$ and the obtained result is equated to zero:

$$
\frac{\partial U}{\partial(\Delta F)}=0
$$

The calculated increase in pre-tensioning force of cable $(\Delta F)$ is obtained using the Eq. (13) as follows:

$$
\Delta F=\frac{q l_{b}^{4} \sin \theta}{4\left(l_{b}^{3} \sin ^{2} \theta+\frac{96(E I)_{b} l_{c}}{(A E)_{c}}+\frac{48 I_{b} l_{b} \cos ^{2} \theta}{A_{b}}\right)} .
$$

If $\sin \theta=\frac{2 y_{0}}{l_{c}}$ and $\cos \theta=\frac{l_{b}}{2 l_{c}}$ (as shown in Figure 4) are replaced in Eq. (13), the moment at fixed end $(M)$ would be $\frac{q l_{b}{ }^{2}}{12}$. This value is the moment at fixed end in beam without cable.

\subsection{The fixed supported beam with the modified V-shaped pattern of cable}

In the fixed supported beam with the modified $\mathrm{V}$ shaped pattern of cable, as shown in Figure 5, assuming the increase in pre-tensioning force of steel cable to be equal to $\Delta F$ in the inclined parts, the increase of pretensioning force of cable in the horizontal part would be $\Delta F \cos \theta$. Therefore, axial force of the beam is equal to $\Delta F \cos \theta$. It should also be mentioned that the fixed supported beam with the modified $\mathrm{V}$-shaped pattern of cable has two degrees of indeterminacy, the increase in pre-tensioning force of the cable $(\Delta F)$, and the moment at fixed end $(M)$ which are exactly the same as those of fixed supported beam with the V-shaped pattern of cable. Calculating the increase in pre-tensioning force

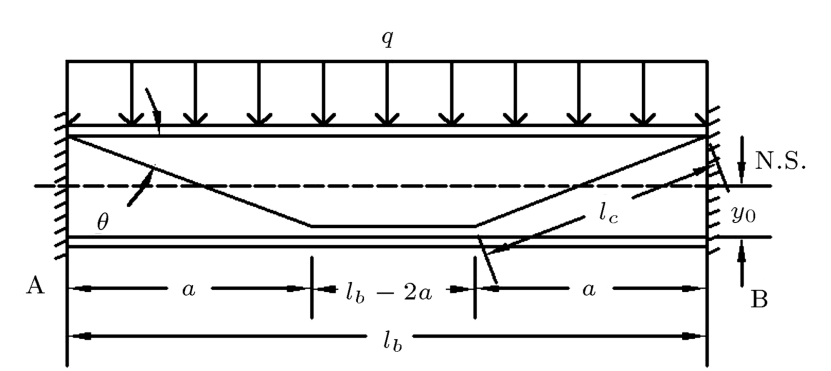

Figure 5. Fixed supported beam along with the modified V-shaped pattern of cable.

of the cable and the moment at fixed end through the method of least work, the relation of total strain energy is differentiated with respect to each of them and the results are equated to zero so that the desired relations are derived.

The bending moment is obtained for fixed supported beam with the modified $\mathrm{V}$-shaped pattern of cable under uniform distributed loading for half of the beam to calculate strain energy caused by bending as follows:

For $0 \leq x \leq a$ range:

$$
M_{1}(x)=-\Delta F \sin \theta x+\Delta F \cos \theta y_{0}-\frac{q x^{2}}{2}+\frac{q l_{b} x}{2}-M \text {. }
$$

For $a \leq x \leq \frac{l_{b}}{2}$ range:

$$
M_{2}(x)=-\Delta F \cos \theta y_{0}-\frac{q x^{2}}{2}+\frac{q l_{b} x}{2}-M .
$$

Considering the symmetry of structure and loading, the total strain energy equation is written in Eq. (18) as shown in Box V. In order to calculate the moment at fixed end $(M)$ through the method of least work, the relation of whole strain energy is differentiated with

$$
\begin{aligned}
U= & 2 \times \frac{1}{2(E I)_{b}}\left\{\begin{array}{l}
\int_{0}^{a}\left(-\Delta F \sin \theta x+\Delta F \cos \theta y_{0}-\frac{q x^{2}}{2}+\frac{q l_{b} x}{2}-M\right)^{2} d x \\
+\int_{a}^{\frac{l_{b}}{2}}\left(-\Delta F \cos \theta y_{0}-\frac{q x^{2}}{2}+\frac{q l_{b} x}{2}-M\right)^{2} d x
\end{array}\right\}+2 \times \frac{\Delta F^{2} l_{c}}{2(A E)_{c}} \\
& +\frac{(\Delta F \cos \theta)^{2}\left(l_{b}-2 a\right)}{2(A E)_{c}}+\frac{(\Delta F \cos \theta)^{2} l_{b}}{2(A E)_{b}}=\frac{1}{(E I)_{b}} \\
& \left\{\begin{array}{l}
\frac{q^{2} l_{b}{ }^{5}}{240}+\frac{\Delta F^{2} a^{3} \sin ^{2} \theta}{3}+\frac{\Delta F^{2} l_{b} y_{0} \cos ^{2} \theta}{2}-\Delta F^{2} y_{0} a^{2} \sin \theta \cos \theta+\frac{q \Delta F a^{4} \sin \theta}{4} \\
-\frac{q \Delta l_{b} a^{3} \sin \theta}{3}-\frac{2 q \Delta F y_{0} a^{3} \cos \theta}{3}+q \Delta F l_{b} y_{0} a^{2} \cos \theta-\frac{q \Delta F l_{b}^{3} y_{0} \cos \theta}{12} \\
+M \Delta F a^{2} \sin \theta-4 M \Delta F y_{0} a \cos \theta+M \Delta F l_{b} y_{0} \cos \theta-\frac{q M l_{b}}{12}+\frac{M^{2} l_{b}}{2}
\end{array}\right\}+\frac{\Delta F^{2} l_{c}}{(A E)_{c}}+\frac{\Delta F^{2}\left(l_{b}-2 a\right) \cos ^{2} \theta}{2(A E)_{c}} \\
& +\frac{\Delta F^{2} l_{b} \cos ^{2} \theta}{2(A E)_{b}} .
\end{aligned}
$$


respect to $M$ and the obtained result is equated to zero:

$$
\frac{\partial U}{\partial M}=0
$$

The calculated bending moment at the fixed end $(M)$ is obtained as follows:

$$
M=\frac{q l_{b}^{2}}{12}-\frac{\Delta F a^{2} \sin \theta}{l_{b}}+\frac{4 \Delta F y_{0} a \cos \theta}{l_{b}}-\Delta F y_{0} \cos \theta \text {. }
$$

In order to calculate the increase of pre-tensioning force of cable $(\Delta F)$ through the method of least work, the relation of whole strain energy is differentiated with respect to $\Delta F$ and the obtained result is equated to zero:

$$
\frac{\partial U}{\partial(\Delta F)}=0
$$

Using Eq. (20), the calculated increase of pretensioning force of cable $(\Delta F)$ is obtained by Eq. (22) as shown in Box VI. Considering Eq. (22), if the length of horizontal cable $\left(l_{b}-2 a\right.$, as shown in Figure $5)$ approaches to zero, Eq. (15) would be obtained for specific status of the V-shaped pattern of cable.

\section{Deflection}

Virtual work method can be used to calculate the deflection of beams with different support conditions without cable as well as different patterns of cable, ignoring the effects of shear and axial forces.

\subsection{Maximum deflection of simply supported and fixed supported beams without cable under uniform distributed loading}

If the length and flexural rigidity of the beam are $l_{b}$ and $(E I)_{b}$, respectively, maximum deflection of simply supported and fixed supported beams without cable under uniform distributed loading $q$ is calculated as follows:

The deflection of the mid span of simply supported beam without cable:

$$
\Delta_{\text {mid }}=\frac{5 q l_{b}{ }^{4}}{384(E I)_{b}} .
$$

The deflection of the mid span of fixed supported beam without cable:

$$
\Delta_{\text {mid }}=\frac{q l_{b}{ }^{4}}{384(E I)_{b}} .
$$

\subsection{Calculating maximum deflection of simply supported beam along with the V-shaped pattern of cable}

Assuming the force of steel cable to be equal to $F$ in the simply supported beam along with the V-shaped pattern of cable, considering the symmetry of structure and loading, the bending moment of simply supported beams along with the V-shaped pattern of cable would be obtained under real loading (Figure 2) for half of the beam as follows:

For $0 \leq x \leq \frac{l_{b}}{2}$ range:

$$
M(x)=-F \sin \theta x+F \cos \theta y_{0}-\frac{q x^{2}}{2}+\frac{q l_{b} x}{2},
$$

where, $F=F_{p t}+\Delta F$ is the total force of the cable; $F_{p t}$ is the pre-tensioning force of the cable; and $\Delta F$ is the increase of pre-tensioning force of the cable.

In analyzing the structure under virtual loading, if the structure is indeterminate, its constraints can be eliminated up to being converted to a stable determinate structure. In the beam and cable system, the cable is a redundancy and can be omitted in analyzing the structure under virtual loading. The bending moment of simply supported beam is obtained under unit virtual load (Figure 6) for half of the beam as follows:

For $0 \leq x \leq \frac{l_{b}}{2}$ range:

$$
m(x)=\frac{x}{2} \text {. }
$$

Considering the symmetry of structure and loading, the deflection of the mid span of simply supported beam along with the $\mathrm{V}$-shaped pattern of cable is calculated as follows:

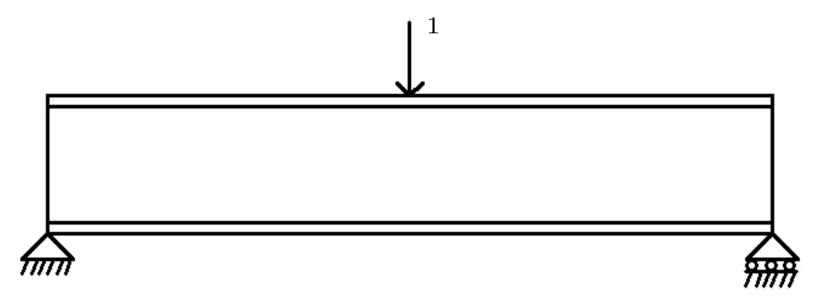

Figure 6. Simply supported beam under unit virtual load.

$$
\Delta F=\frac{-3 q l_{b} a^{4} \sin \theta+4 q l_{b}{ }^{2} a^{3} \sin \theta-q l_{b}{ }^{3} a^{2} \sin \theta+8 q l_{b} y_{0} a^{3} \cos \theta-12 q l_{b}{ }^{2} y_{0} a^{2} \cos \theta+4 q l_{b}{ }^{3} y_{0} a \cos \theta}{4\left(\begin{array}{l}
-3 a^{4} \sin ^{2} \theta+2 l_{b} a^{3} \sin ^{2} \theta-48 y_{0}{ }^{2} a^{2} \cos ^{2} \theta+24 l_{b} y_{0}{ }^{2} a \cos ^{2} \theta+24 y_{0} a^{3} \sin \theta \cos \theta \\
-12 l_{b} y_{0} a^{2} \sin \theta \cos \theta+\frac{3 l_{b}(E I)_{b}}{(A E)_{c}}\left[2 l_{c}+\left(l_{b}-2 a\right) \cos ^{2} \theta\right]+\frac{3 I_{b} l_{b}{ }^{2} \cos ^{2} \theta}{A_{b}}
\end{array}\right)}
$$




$$
\begin{aligned}
1 \times \Delta & =\int \frac{M(x) m(x)}{E I} d x=\frac{2}{(E I)_{b}} \int_{0}^{\frac{l_{b}}{2}} \\
& \left(-F \sin \theta x+F \cos \theta y_{0}-\frac{q x^{2}}{2}+\frac{q l_{b} x}{2}\right)\left(\frac{x}{2}\right) d x \\
& =\frac{1}{(E I)_{b}}\left[\frac{5 q l_{b}{ }^{4}}{384}-\frac{F l_{b}{ }^{3} \sin \theta}{24}+\frac{F l_{b}{ }^{2} y_{0} \cos \theta}{8}\right] .
\end{aligned}
$$

\subsection{Calculating maximum deflection of simply supported beam along with the modified $V$-shaped pattern of cable}

Assuming the force of steel cable to be equal to $F$ in the inclined parts, the force of cable in the horizontal part would be $F \cos \theta$. Considering the symmetry of structure and loading (Figure 3 ), bending moment of simply supported beam along with the modified $\mathrm{V}$ shaped pattern of cable is obtained under real loading for the half of beam as follows:

For $0 \leq x \leq a$ range:

$$
M_{1}(x)=-F \sin \theta x+F \cos \theta y_{0}-\frac{q x^{2}}{2}+\frac{q l_{b} x}{2}
$$

For $a \leq x \leq \frac{l_{b}}{2}$ range:

$$
M_{2}(x)=-F \cos \theta y_{0}-\frac{q x^{2}}{2}+\frac{q l_{b} x}{2} .
$$

Bending moment of simply supported beam under unit virtual loading is calculated using Eq. (26).

Considering the symmetry of structure and loading, the deflection of the mid span of simply supported beam along with the modified V-shaped pattern of cable is calculated by Eq. (30) as shown in Box VII, where, $a$ is the distance between support and cable slope change region (horizontal projection of inclined cable).

Considering Eq. (30), if the length of horizontal cable $\left(l_{b}-2 a\right.$, as shown in Figure 3$)$ approaches zero, then Eq. (27) would be obtained for specific status of the V-shaped pattern of cable.

\subsection{Calculating maximum deflection of fixed supported beam along with the V-shaped pattern of cable}

Assuming the force of steel cable to be equal to $F$ and the moment at fixed end $(M)$ to be equal to $\frac{q l_{b}{ }^{2}}{12}$, as shown in Section 3.3, the bending moment of fixed supported beam along with the V-shaped pattern of cable would be obtained under real loading for half of the beam (Figure 4) as follows:

For $0 \leq x \leq \frac{l_{b}}{2}$ range:

$$
\begin{aligned}
M(x)= & -F \sin \theta x+F \cos \theta y_{0}-\frac{q x^{2}}{2}+\frac{q l_{b} x}{2}-M \\
= & -F \sin \theta x+F \cos \theta y_{0}-\frac{q x^{2}}{2}+\frac{q l_{b} x}{2} \\
& -\frac{q l_{b}^{2}}{12} .
\end{aligned}
$$

Cable is a redundancy in the analysis of beam-cable system under virtual loading and can be omitted. Considering the symmetry of structure and loading, bending moment of fixed supported beam under unit virtual loading (Figure 7 ) is obtained for half of the beam as follows:

For $0 \leq x \leq \frac{l_{b}}{2}$ range:

$$
m(x)=\frac{x}{2}-\frac{l_{b}}{8} \text {. }
$$

Deflection of the mid span of fixed supported beam along with the $\mathrm{V}$-shaped pattern of cable is calculated as follows:

$$
\begin{aligned}
& 1 \times \Delta=\int \frac{M(x) m(x)}{E I} d x=\frac{2}{(E I)_{b}} \int_{0}^{\frac{l_{b}}{2}} \\
& \left(-F \sin \theta x+F \cos \theta y_{0}-\frac{q x^{2}}{2}+\frac{q l_{b} x}{2}-\frac{q l_{b}{ }^{2}}{12}\right) \\
& \left(\frac{x}{2}-\frac{l_{b}}{8}\right) d x=\frac{1}{(E I)_{b}}\left[\frac{q l_{b}{ }^{4}}{384}-\frac{F l_{b}^{3} \sin \theta}{96}\right] .
\end{aligned}
$$

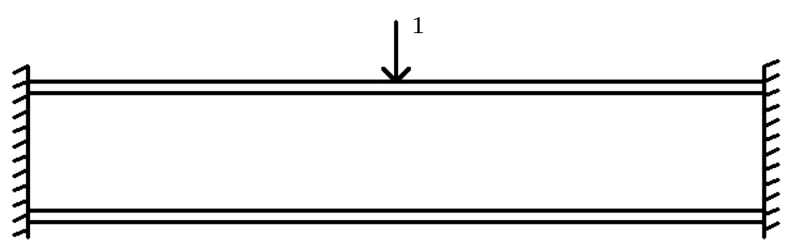

Figure 7. Fixed supported beam under unit virtual loading.

$$
\begin{aligned}
1 \times \Delta & =\int \frac{M(x) m(x)}{E I} d x=\frac{2}{(E I)_{b}}\left[\begin{array}{l}
\int_{0}^{a}\left(-F \sin \theta x+F \cos \theta y_{0}-\frac{q x^{2}}{2}+\frac{q l_{b} x}{2}\right)\left(\frac{x}{2}\right) d x \\
+\int_{a}^{\frac{x_{b}}{2}}\left(-F \cos \theta y_{0}-\frac{q x^{2}}{2}+\frac{q l_{b} x}{2}\right)\left(\frac{x}{2}\right) d x
\end{array}\right] \\
& =\frac{1}{(E I)_{b}}\left[\frac{5 q l_{b}}{384}-\frac{F a^{3} \sin \theta}{3}+F y_{0} a^{2} \cos \theta-\frac{F l_{b}^{2} y_{0} \cos \theta}{8}\right] .
\end{aligned}
$$




\subsection{Calculating maximum deflection of fixed supported beam along with the modified $V$-shaped pattern of cable}

Assuming the force of steel cable to be equal to $F$ in the inclined parts, the force of cable in the horizontal part would be $F \cos \theta$. The moment at fixed end $(M)$ is obtained as follows (as shown in Section 3.4):

$$
M=\frac{q l_{b}{ }^{2}}{12}-\frac{F a^{2} \sin \theta}{l_{b}}+\frac{4 F y_{0} a \cos \theta}{l_{b}}-F y_{0} \cos \theta .
$$

The bending moment of fixed supported beam along with the modified V-shaped pattern of cable under real loading (Figure 5) is obtained for half of the beam as follows:

For $0 \leq x \leq a$ range:

$$
\begin{aligned}
M_{1}(x)= & -F \sin \theta x+F \cos \theta y_{0}-\frac{q x^{2}}{2}+\frac{q l_{b} x}{2}-M \\
= & -F \sin \theta x+2 F \cos \theta y_{0}-\frac{q x^{2}}{2}+\frac{q l_{b} x}{2} \\
& -\frac{q l_{b}^{2}}{12}+\frac{F a^{2} \sin \theta}{l_{b}}-\frac{4 F y_{0} a \cos \theta}{l_{b}}
\end{aligned}
$$

For $a \leq x \leq \frac{l_{b}}{2}$ range:

$$
\begin{aligned}
M_{2}(x) & =-F \cos \theta y_{0}-\frac{q x^{2}}{2}+\frac{q l_{b} x}{2}-M=-\frac{q x^{2}}{2} \\
& +\frac{q l_{b} x}{2}-\frac{q l_{b}{ }^{2}}{12}+\frac{F a^{2} \sin \theta}{l_{b}}-\frac{4 F y_{0} a \cos \theta}{l_{b}} .
\end{aligned}
$$

Bending moment of fixed supported beam under unit virtual loading is obtained through Eq. (32).

The deflection of mid span of fixed supported beam along with the modified $\mathrm{V}$-shaped pattern of cable is calculated by Eq.(37) is shown in Box VIII. With respect to Eq. (37), if the horizontal cable length $\left(l_{b}-2 a\right.$, as shown in Figure 5$)$ approaches zero, Eq. (33) would be obtained for specific status of the V-shaped pattern of cable.

\section{Calculating the required cross-sectional area of steel cable to reach allowable deflection}

In this section, the required cross-sectional area of steel cable with specified pre-tensioning force $F_{p t}$ is calculated for steel beams with different support conditions in which the maximum deflection is not within the allowable range so that by adding cable, the maximum deflection of the beam along with cable reaches allowable amount.

\subsection{Calculating the required cross-sectional area of steel cable to reach allowable deflection in simply supported beam along with the V-shaped pattern of cable}

For calculating the required cross-sectional area of steel cable with specified pre-tensioning force $F_{p t}$ to reach allowable deflection, the maximum deflection of simply supported beam along with the V-shaped pattern of cable, according to Eq. (27), must be equal to allowable amount $\Delta_{a}$ as follows:

$$
\Delta_{a}=\frac{1}{(E I)_{b}}\left[\frac{5 q l_{b}{ }^{4}}{384}-\frac{F l_{b}{ }^{3} \sin \theta}{24}+\frac{F l_{b}{ }^{2} y_{0} \cos \theta}{8}\right] \text {. }
$$

In Eq. (38), $\frac{5 q l_{b}{ }^{4}}{384(E I)_{b}}$ is the midspan deflection of simply supported beam without cable and is replaced by Eq. (23).

$$
\Delta_{a}=\Delta_{m i d}+\frac{1}{(E I)_{b}}\left[-\frac{F l_{b}^{3} \sin \theta}{24}+\frac{F l_{b}^{2} y_{0} \cos \theta}{8}\right] .
$$

From Eq. (39), the total cable force is obtained as follows:

$$
F=\frac{24(E I)_{b}\left(\Delta_{m i d}-\Delta_{a}\right)}{l_{b}^{3} \sin \theta-3 l_{b}^{2} y_{0} \cos \theta}=\alpha\left(\Delta_{m i d}-\Delta_{a}\right) .
$$

In Eq. (40), $\alpha$ is as follows:

$$
\alpha=\frac{24(E I)_{b}}{l_{b}{ }^{3} \sin \theta-3 l_{b}{ }^{2} y_{0} \cos \theta} .
$$

The increase in pre-tensioning force of the cable, $\Delta F$, according to Eq. (4) is obtained by Eq. (42) as shown

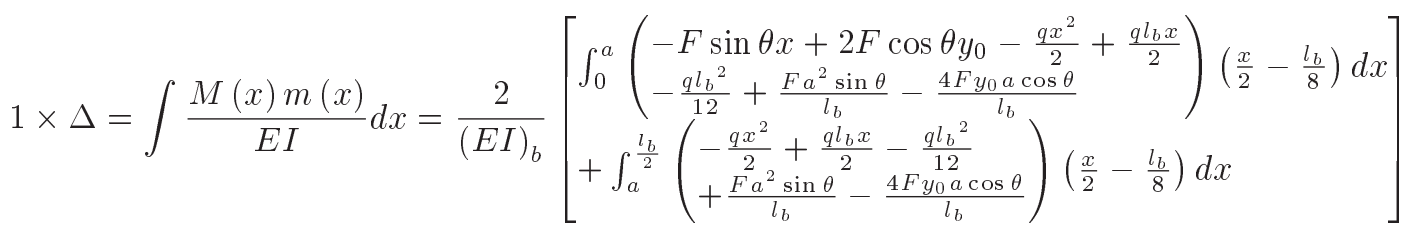

$$
\begin{aligned}
& =\frac{1}{(E I)_{b}}\left[\frac{q l_{b}^{4}}{384}-\frac{F a^{3} \sin \theta}{3}+\frac{F l_{b} a^{2} \sin \theta}{8}+F y_{0} a^{2} \cos \theta-\frac{F l_{b} y_{0} a \cos \theta}{2}\right] \text {. }
\end{aligned}
$$




$$
\Delta F=\frac{5 q l_{b}{ }^{4} \sin \theta-16 q l_{b}{ }^{3} y_{0} \cos \theta}{16\left(l_{b}{ }^{3} \sin ^{2} \theta+12 l_{b} y_{0}{ }^{2} \cos ^{2} \theta-6 l_{b}{ }^{2} y_{0} \sin \theta \cos \theta+\frac{24(E I)_{b} l_{c}}{(A E)_{c}}+\frac{12 I_{b} l_{b} \cos ^{2} \theta}{A_{b}}\right)}=\frac{\beta}{\gamma+\frac{\mu}{A_{c}}} .
$$

\section{Box IX}

in Box IX. In Eq. (42), $\beta, \gamma$, and $\mu$ are defined as follows:

$$
\begin{aligned}
\beta= & 5 q l_{b}{ }^{4} \sin \theta-16 q l_{b}{ }^{3} y_{0} \cos \theta \\
\gamma= & 16\left(l_{b}{ }^{3} \sin ^{2} \theta+12 l_{b} y_{0}{ }^{2} \cos ^{2} \theta-6 l_{b}{ }^{2} y_{0} \sin \theta \cos \theta\right. \\
& \left.+\frac{12 I_{b} l_{b} \cos ^{2} \theta}{A_{b}}\right) \\
\mu= & 16\left(\frac{24(E I)_{b} l_{c}}{E_{c}}\right) .
\end{aligned}
$$

From Eq. (42), the required cross-sectional area of the cable $A_{c}$ is obtained as follows:

$$
A_{c}=\frac{\mu \Delta F}{\beta-\gamma \Delta F} \text {. }
$$

The increase in pre-tensioning force of cable, $\Delta F$, with regards to the total cable force is obtained according to Eq. (40) as follows:

$$
\Delta F=F-F_{p t}=\alpha\left(\Delta_{m i d}-\Delta_{a}\right)-F_{p t} .
$$

By replacing Eq. (47) in Eq. (46), the required crosssectional area of the cable with specified pre-tensioning force $F_{p t}$ to reach allowable deflection in simply supported beam along with the V-shaped pattern of cable is obtained as follows:

$$
A_{c}=\frac{\mu\left(\alpha\left(\Delta_{\text {mid }}-\Delta_{a}\right)-F_{p t}\right)}{\beta-\gamma\left(\alpha\left(\Delta_{\text {mid }}-\Delta_{a}\right)-F_{p t}\right)} .
$$

\subsection{Calculating the required cross-sectional area of steel cable to reach allowable deflection in simply supported beam along with the modified $V$-shaped pattern of cable}

For calculating the required cross-sectional area of steel cable with specified pre-tensioning force $F_{p t}$ to reach allowable deflection, the maximum deflection of simply supported beam along with the modified V-shaped pattern of cable, according to Eq. (30) by replacing Eq. (23), must be equal to allowable amount $\Delta_{a}$ as follows:

$$
\begin{aligned}
\Delta_{a} & =\Delta_{m i d}+\frac{1}{(E I)_{b}}\left[-\frac{F a^{3} \sin \theta}{3}+F y_{0} a^{2} \cos \theta\right. \\
& \left.-\frac{F l_{b}^{2} y_{0} \cos \theta}{8}\right] .
\end{aligned}
$$

From Eq. (49), the total cable force is obtained as follows:

$$
\begin{aligned}
F & =\frac{24(E I)_{b}\left(\Delta_{\text {mid }}-\Delta_{a}\right)}{8 a^{3} \sin \theta-24 y_{0} a^{2} \cos \theta+3 l_{b}{ }^{2} y_{0} \cos \theta} \\
& =\alpha\left(\Delta_{\text {mid }}-\Delta_{a}\right) .
\end{aligned}
$$

In Eq. (50), $\alpha$ is defined as follows:

$$
\alpha=\frac{24(E I)_{b}}{8 a^{3} \sin \theta-24 y_{0} a^{2} \cos \theta+3 l_{b}^{2} y_{0} \cos \theta} .
$$

The increase in pre-tensioning force of cable $\Delta F$ according to Eq. (9) is obtained by Eq. (52) as shown in Box X. In Eq. (52), $\beta, \gamma$ and $\mu$ are defined as follows:

$$
\begin{aligned}
\beta= & -3 q a^{4} \sin \theta+4 q l_{b} a^{3} \sin \theta+8 q y_{0} a^{3} \cos \theta \\
& -12 q l_{b} y_{0} a^{2} \cos \theta+q l_{b}^{3} y_{0} \cos \theta, \\
\gamma= & 4\left(2 a^{3} \sin ^{2} \theta+3 l_{b} y_{0}^{2} \cos ^{2} \theta-6 y_{0} a^{2} \sin \theta \cos \theta\right. \\
& \left.+\frac{3 I_{b} l_{b} \cos ^{2} \theta}{A_{b}}\right), \\
\mu= & 4\left(\frac{3(E I)_{b}}{E_{c}}\left[2 l_{c}+\left(l_{b}-2 a\right) \cos ^{2} \theta\right]\right) .
\end{aligned}
$$

$$
\Delta F=\frac{-3 q a^{4} \sin \theta+4 q l_{b} a^{3} \sin \theta+8 q y_{0} a^{3} \cos \theta-12 q l_{b} y_{0} a^{2} \cos \theta+q l_{b}^{3} y_{0} \cos \theta}{4\left(\begin{array}{l}
2 a^{3} \sin ^{2} \theta+3 l_{b} y_{0}{ }^{2} \cos ^{2} \theta-6 y_{0} a^{2} \sin \theta \cos \theta \\
+\frac{3(E I)_{b}}{(A E)_{c}}\left[2 l_{c}+\left(l_{b}-2 a\right) \cos ^{2} \theta\right]+\frac{3 I_{b} l_{b} \cos ^{2} \theta}{A_{b}}
\end{array}\right)}=\frac{\beta}{\gamma+\frac{\mu}{A_{c}}} .
$$


From Eq. (52), the required cross-sectional area of cable $A_{c}$ is obtained as follows:

$$
A_{c}=\frac{\mu \Delta F}{\beta-\gamma \Delta F} \text {. }
$$

The increase in pre-tensioning force of cable $\Delta F$ regarding to the total cable force is obtained in accordance with Eq. (50) as follows:

$$
\Delta F=F-F_{p t}=\alpha\left(\Delta_{m i d}-\Delta_{a}\right)-F_{p t} .
$$

By replacing Eq. (57) in Eq. (56), the required crosssectional area of cable with specified pre-tensioning force $F_{p t}$ to reach allowable deflection in simply supported beam along with the modified V-shaped pattern of cable is obtained as follows:

$$
A_{c}=\frac{\mu\left(\alpha\left(\Delta_{\text {mid }}-\Delta_{a}\right)-F_{p t}\right)}{\beta-\gamma\left(\alpha\left(\Delta_{\text {mid }}-\Delta_{a}\right)-F_{p t}\right)} .
$$

\subsection{Calculating the required cross-sectional area of steel cable to reach the allowable deflection in fixed supported beam along with the V-shaped pattern of cable}

Calculating the required cross-sectional area of steel cable with specified pre-tensioning force $F_{p t}$ to reach allowable deflection, the maximum deflection of fixed supported beam along with the V-shaped pattern of cable, according to Eq. (33) by replacing Eq. (24), must be equal to allowable amount $\Delta_{a}$ as follows:

$$
\Delta_{a}=\Delta_{m i d}-\frac{F l_{b}{ }^{3} \sin \theta}{96(E I)_{b}} .
$$

From Eq. (59), the total cable force is obtained as follows:

$$
F=\frac{96(E I)_{b}\left(\Delta_{\text {mid }}-\Delta_{a}\right)}{l_{b}^{3} \sin \theta}=\alpha\left(\Delta_{\text {mid }}-\Delta_{a}\right) .
$$

In Eq. (60), $\alpha$ is as follows:

$$
\alpha=\frac{96(E I)_{b}}{l_{b}^{3} \sin \theta} .
$$

The increase in pre-tensioning force of cable $\Delta F$ according to Eq. (15) is obtained as follows:

$$
\begin{aligned}
\Delta F & =\frac{q l_{b}{ }^{4} \sin \theta}{4\left(l_{b}{ }^{3} \sin ^{2} \theta+\frac{96(E I)_{b} l_{c}}{(A E)_{c}}+\frac{48 I_{b} l_{b} \cos ^{2} \theta}{A_{b}}\right)} \\
& =\frac{\beta}{\gamma+\frac{\mu}{A_{c}}} .
\end{aligned}
$$

In Eq. (62), $\beta, \gamma$, and $\mu$ are as follows:

$$
\beta=q l_{b}^{4} \sin \theta,
$$

$$
\begin{aligned}
& \gamma=4\left(l_{b}{ }^{3} \sin ^{2} \theta+\frac{48 I_{b} l_{b} \cos ^{2} \theta}{A_{b}}\right), \\
& \mu=4\left(\frac{96(E I)_{b} l_{c}}{E_{c}}\right) .
\end{aligned}
$$

From Eq. (62), the required cross-sectional area of cable $A_{c}$ is obtained as follows:

$$
A_{c}=\frac{\mu \Delta F}{\beta-\gamma \Delta F} .
$$

The increase in pre-tensioning force of cable $\Delta F$ with regards to total cable force in accordance with Eq. (60) is obtained as follows:

$$
\Delta F=F-F_{p t}=\alpha\left(\Delta_{m i d}-\Delta_{a}\right)-F_{p t} .
$$

By replacing Eq. (67) in Eq. (66), the required crosssectional area of cable with specified pre-tensioning force $F_{p t}$ to reach allowable deflection in fixed supported beam along with the V-shaped pattern of cable is obtained as follows:

$$
A_{c}=\frac{\mu\left(\alpha\left(\Delta_{\text {mid }}-\Delta_{a}\right)-F_{p t}\right)}{\beta-\gamma\left(\alpha\left(\Delta_{\text {mid }}-\Delta_{a}\right)-F_{p t}\right)} .
$$

\subsection{Calculating the required cross-sectional area of steel cable to reach allowable deflection in fixed supported beam along with the modified $V$-shaped pattern of cable}

For calculating the required cross-sectional area of steel cable with specified pre-tensioning force $F_{p t}$ to reach the allowable deflection, the maximum deflection of fixed supported beam along with the modified Vshaped pattern of cable, according to Eq. (37) by replacing Eq. (24), must be equal to allowable amount $\Delta_{a}$ as follows:

$$
\begin{aligned}
\Delta_{a}= & \Delta_{\text {mid }}+\frac{1}{(E I)_{b}}\left[-\frac{F a^{3} \sin \theta}{3}+\frac{F l_{b} a^{2} \sin \theta}{8}\right. \\
& \left.+F y_{0} a^{2} \cos \theta-\frac{F l_{b} y_{0} a \cos \theta}{2}\right] .
\end{aligned}
$$

From Eq. (69), the total cable force is obtained by Eq. (70) as shown in Box XI. In Eq. (70), $\alpha$ is defined as follows:

$$
\begin{aligned}
& \alpha= \\
& \frac{24(E I)_{b}}{8 a^{3} \sin \theta-3 l_{b} a^{2} \sin \theta-24 y_{0} a^{2} \cos \theta+12 l_{b} y_{0} a \cos \theta} .
\end{aligned}
$$

The increase in pre-tensioning force of cable $\Delta F$ according to Eq. (22) is obtained by Eq. (72) as shown in Box XII. In Eq. (72), $\beta, \gamma$, and $\mu$ are defined as follows: 


$$
F=\frac{24(E I)_{b}\left(\Delta_{m i d}-\Delta_{a}\right)}{8 a^{3} \sin \theta-3 l_{b} a^{2} \sin \theta-24 y_{0} a^{2} \cos \theta+12 l_{b} y_{0} a \cos \theta}=\alpha\left(\Delta_{m i d}-\Delta_{a}\right)
$$

\section{Box XI}

$$
\Delta F=\frac{\begin{array}{l}
-3 q l_{b} a^{4} \sin \theta+4 q l_{b}^{2} a^{3} \sin \theta-q l_{b}^{3} a^{2} \sin \theta \\
+8 q l_{b} y_{0} a^{3} \cos \theta-12 q l_{b}^{2} y_{0} a^{2} \cos \theta+4 q l_{b}^{3} y_{0} a \cos \theta
\end{array}}{4\left(\begin{array}{l}
-3 a^{4} \sin ^{2} \theta+2 l_{b} a^{3} \sin ^{2} \theta-48 y_{0}{ }^{2} a^{2} \cos ^{2} \theta+24 l_{b} y_{0}{ }^{2} a \cos ^{2} \theta \\
+24 y_{0} a^{3} \sin \theta \cos \theta-12 l_{b} y_{0} a^{2} \sin \theta \cos \theta \\
+\frac{3 l_{b}(E I)_{b}}{(A E)_{c}}\left[2 l_{c}+\left(l_{b}-2 a\right) \cos ^{2} \theta\right]+\frac{3 I_{b} l_{b} \cos ^{2} \theta}{A_{b}}
\end{array}\right)}=\frac{\beta}{\gamma+\frac{\mu}{A_{c}}} .
$$

Box XII

$$
\begin{aligned}
\beta= & -3 q l_{b} a^{4} \sin \theta+4 q l_{b}^{2} a^{3} \sin \theta-q l_{b}^{3} a^{2} \sin \theta \\
& +8 q l_{b} y_{0} a^{3} \cos \theta-12 q l_{b}^{2} y_{0} a^{2} \cos \theta+4 q l_{b}^{3} y_{0} a \cos \theta,
\end{aligned}
$$

Eq. (74) is shown in Box XIII.

$$
\mu=4\left(\frac{3 l_{b}(E I)_{b}}{E_{c}}\left[2 l_{c}+\left(l_{b}-2 a\right) \cos ^{2} \theta\right]\right)
$$

From Eq. (72), the required cross-sectional area of cable $A_{c}$ is obtained as follows:

$$
A_{c}=\frac{\mu \Delta F}{\beta-\gamma \Delta F} \text {. }
$$

The increase in pre-tensioning force of cable $\Delta F$ with regards to total cable force in accordance with Eq. (70) is obtained as follows:

$$
\Delta F=F-F_{p t}=\alpha\left(\Delta_{m i d}-\Delta_{a}\right)-F_{p t} .
$$

By replacing Eq. (77) in Eq. (76), the required crosssectional area of cable with specified pre-tensioning force $F_{p t}$ to reach the allowable deflection in the fixed supported beam along with the modified V-shaped pattern of cable is obtained as follows:

$$
A_{c}=\frac{\mu\left(\alpha\left(\Delta_{m i d}-\Delta_{a}\right)-F_{p t}\right)}{\beta-\gamma\left(\alpha\left(\Delta_{m i d}-\Delta_{a}\right)-F_{p t}\right)}
$$

\section{Finite element modeling of steel beams pre-stressed with steel cable}

Simply supported and fixed supported beams have been designed based on load and resistance factor design method using AISC360-10 code [23]. Simply supported beam has been designed in such a way that the maximum deflections under dead and live loads are greater than the allowable deflection $\left(\frac{1}{240}\right.$ of the beam length). However, due to the high stiffness of fixed supported beams, usually the maximum deflection is less than the allowable limit. Therefore, a fixed supported beam has been merely designed to show the effects of cable. Table 1 presents the properties of the beams with various support conditions as well as related allowable and maximum deflections under service load. It should be noted that the length of loading span is $1.5 \mathrm{~m}$ for the beams with different support conditions; dead and live loads are 450 and $200 \mathrm{~kg} / \mathrm{m}^{2}$ respectively.

The beams are modeled in the finite element Abaqus software under uniform distributed loads, considering different support conditions without cable and with different patterns of cable. Figure 8 presents finite element models of the beams along with different patterns of the cable. The beams and cables have been modeled in 3-dimentional space with shell and truss elements (as wire) respectively. The weld's connector is used to connect the cable to the top flange of the beam at two ends providing a perfect connection

$$
\gamma=4\left(\begin{array}{l}
-3 a^{4} \sin ^{2} \theta+2 l_{b} a^{3} \sin ^{2} \theta-48 y_{0}{ }^{2} a^{2} \cos ^{2} \theta+24 l_{b} y_{0}{ }^{2} a \cos ^{2} \theta+24 y_{0} a^{3} \sin \theta \cos \theta \\
-12 l_{b} y_{0} a^{2} \sin \theta \cos \theta+\frac{3 I_{b} l_{b}^{2} \cos ^{2} \theta}{A_{b}}
\end{array}\right)
$$


Table 1. Properties and deflections of beams with different support conditions.

\begin{tabular}{ccccc}
\hline Type of beam & $\begin{array}{c}\text { Beam span } \\
\text { length } \mathbf{( m )}\end{array}$ & $\begin{array}{c}\text { Cross-section } \\
\text { of beam }\end{array}$ & $\begin{array}{c}\text { Maximum } \\
\text { deflection } \mathbf{( c m )}\end{array}$ & $\begin{array}{c}\text { Allowable } \\
\text { deflection } \mathbf{( c m )}\end{array}$ \\
\hline Simply supported beam & 12 & IPE400 & 5.691 & 5 \\
Fixed supported beam & 12 & IPE330 & 2.237 & 5 \\
\hline
\end{tabular}

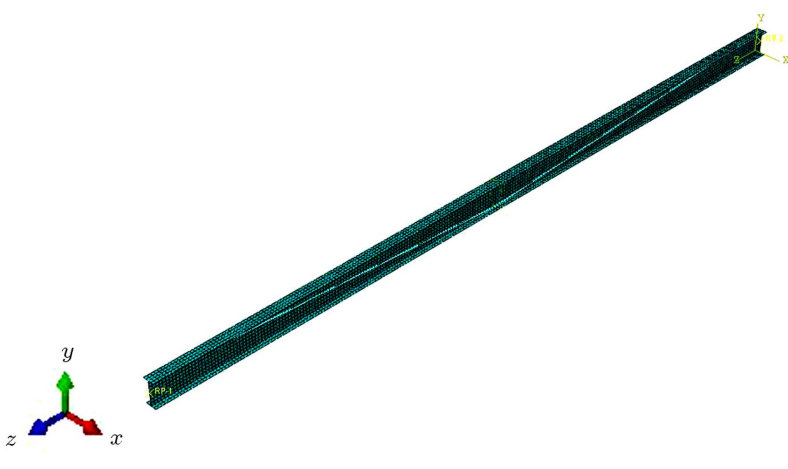

(a)

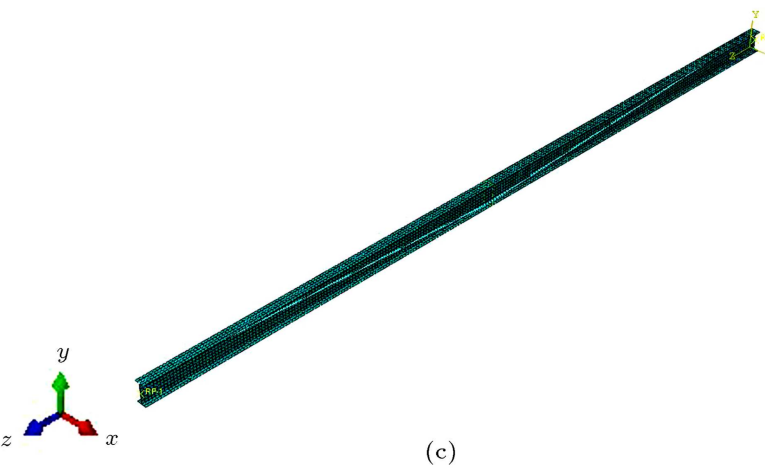

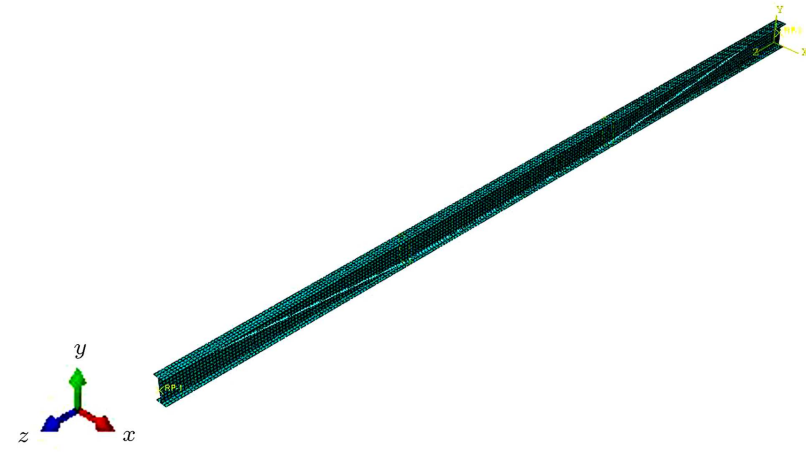

(b)

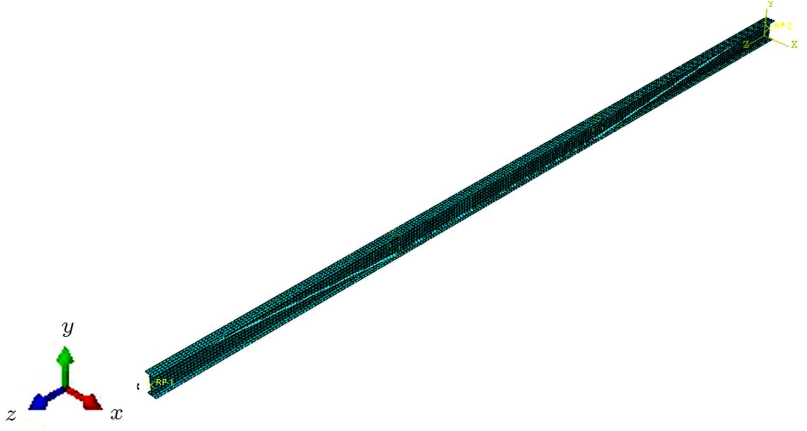

(d)

Figure 8. Finite element models of the beams along with different patterns of cable: (a) simply supported beam along with the V-shaped pattern of cable, (b) simply supported beam along with the modified V-shaped pattern of cable, (c) fixed supported beam along with the V-shaped pattern of cable, and (d) fixed supported beam along with the modified V-shaped pattern of cable.

between two nodes. Moreover, coupling constraint is used to connect the cable to the bottom flange of the beam so as to model the deviator's behavior. Uniform distributed load is applied as a surface traction type on the top flange. Predefined field tool is used to create the initial pre-tensioning stress in the cable as well. The initial pre-tensioning stress is applied to the cable in Abaqus software and uniform distributed loading is applied. Because the steel beam is not rigid and the cable creates the compression force, the steel beam length is decreased. So, the amount of the initial pre-tensioning stress of cable is lost. Therefore, the amount of the initial pre-tensioning stress is considered to be much greater in Abaqus software to reach the desired pre-stressing value after its loss. Figure 9 presents the locations of cables in the beams with different support conditions.

For better presenting the behavior of beams with different support conditions and different patterns of cable, first they have been modeled in the software without cable, and then with different patterns of cable; and the obtained results have been compared with each other. The materials of beam and cable are defined as linearly elastic in the software. The steel material of beams considered in this research is ST-37; yield stress is $240 \mathrm{MPa}$; modulus of elasticity of steel is $200 \mathrm{GPa}$; Poisson's ratio is 0.3 ; density of steel is $7850 \mathrm{~kg} / \mathrm{m}^{3}$. The material of steel cable is in accordance with ASTM A416M standard [24]. 7-wire strand (grade 270 (1860)) is considered for steel cable with low relaxation, minimum ultimate strength $\left(f_{p u}\right)$ of $270 \mathrm{ksi}(1860 \mathrm{MPa})$, minimum yield strength at $1 \%$ extension of $52.74 \mathrm{kip}(234.6 \mathrm{KN})$, elasticity module of $28.5 \times 10^{6} \mathrm{psi}(196501.8 \mathrm{MPa})$ and Poisson's ratio of 0.3 .

Adding different patterns of cable to the beams 


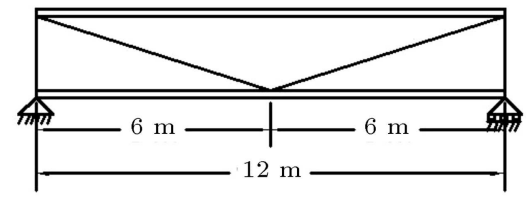

(a)

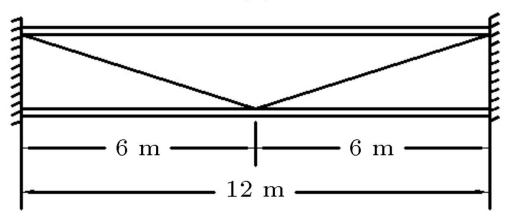

(c)

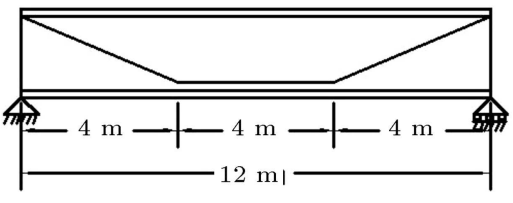

(b)

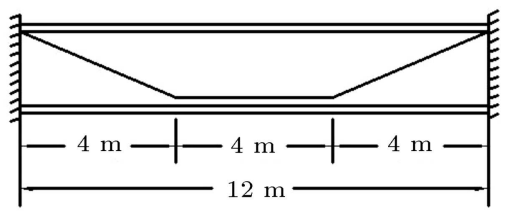

(d)

Figure 9. The locations of cables in the beams: (a) Simply supported beam along with the V-shaped pattern of cable, (b) simply supported beam along with the modified V-shaped pattern of cable, (c) fixed supported beam along with the V-shaped pattern of cable, and (d) fixed supported beam along with the modified V-shaped pattern of cable.

converts them to beam-columns because the horizontal component of the cable force creates an axial force in the beams. To prevent the beam buckling about the longitudinal axis, simply supported beam is considered with 4 lateral braces in equal distances along the beam length and fixed supported beam with 2 lateral braces in equal distances along the beam length. The beams are designed according to AISC360-10 so as to take the simultaneous effects of axial force and bending moment into account.

\section{Verification of theoretical relations of deflection with results of Abaqus models}

Static general analysis of Abaqus software has been used to analyze the beams with different support conditions (Table 1), without cable and with different patterns of cable.

The cross-sectional area of steel cable is considered as 7-wire strand with low relaxation for simply supported and fixed supported beams with equal numbers of cables at both sides of the webs with the cross section areas of $140 \mathrm{~mm}^{2}$ and $98.71 \mathrm{~mm}^{2}$, for each cable respectively. These values are considered according to ASTM A416 standard and presented in Table 2.

Pre-tensioning of the steel cable is considered as $600 \mathrm{MPa}$. Controlling the accuracy of theoretical relations, maximum deflections obtained from modeling are compared to those of the theoretical relations for the beams with different support conditions and different patterns of cable.

The results of maximum deflection obtained from modeling are compared: 1) with those of Eqs. (23), (27), and (30) for simply supported beams without cable and with different patterns of cable; and 2) with those of Eqs. (24), (33), and (37) for fixed supported beams without cable and with different patterns of cable, Table 3.

As presented in Table 3, maximum deflection of the beams without cable obtained from modeling is slightly more than those of theoretical relations. The reason is that the beam has been modeled in Abaqus software in the form of shell; and therefore beam haunch cannot be modeled. By decreasing the moment of inertia of beam section in the software, maximum deflection of the beam without cable, obtained from modeling, becomes slightly more than those of theoretical relations. Maximum deflection of the beams along with cable, obtained from modeling, is very close to those of theoretical equations. Considering the theoretical relations of increasing the pre-tensioning of the cable, reducing the moment of inertia in Abaqus software due to not modeling the beam haunch results in obtaining more increase in the pre-tensioning force in modeling than those of theoretical equations.

Consequently, the steel beam deflection related to the increase in pre-tensioning force of the cable, obtained from modeling, is slightly more than those of theoretical relations. Therefore, in calculating the deflections of beams along with cable and different support conditions, the errors arise from different deflections of the beams along with cable, related to the status of increasing in pre-tensioning force of the cable, obtained from modelings and those of theoretical equations operate as opposed to those of the beams without cable related to the uniform distributed loading. Consequently, they cancel out the effects of each other.

Table 2. Cross-sectional area of steel cable for beams with different support conditions.

\begin{tabular}{ccc}
\hline Type of beam & Simply supported beam & Fixed supported beam \\
\hline Total cross-section area of steel cable $\left(\mathrm{mm}^{2}\right)$ & 560 & 395 \\
\hline
\end{tabular}


Table 3. Maximum deflection values obtained from modeling and theoretical equations for the beams with different support conditions without cable and with different cable patterns.

\begin{tabular}{|c|c|c|c|c|c|}
\hline & Type of beam & $\begin{array}{c}\text { Maximum } \\
\text { deflection of } \\
\text { beam obtained } \\
\text { from modeling } \\
(\mathrm{cm})\end{array}$ & $\begin{array}{c}\text { Maximum } \\
\text { deflection of } \\
\text { beam obtained } \\
\text { from theoretical } \\
\text { equations } \\
(\mathrm{cm})\end{array}$ & $\begin{array}{l}\text { Percentage- } \\
\text { wise } \\
\text { difference }\end{array}$ & $\begin{array}{c}\text { Allowable } \\
\text { deflection } \\
\text { (cm) }\end{array}$ \\
\hline \multirow{3}{*}{$\begin{array}{c}\text { Simply supported } \\
\text { beam }\end{array}$} & Without cable & 5.877 & 5.691 & 3.3 & 5 \\
\hline & With V-shaped cable pattern & 4.898 & 4.851 & 0.97 & \\
\hline & With modified V-shaped cable pattern & 3.768 & 3.833 & 1.7 & \\
\hline \multirow{3}{*}{$\begin{array}{c}\text { Fixed supported } \\
\text { beam }\end{array}$} & Without cable & 2.381 & 2.237 & 6.4 & 5 \\
\hline & With V-shaped cable pattern & 1.253 & 1.258 & 0.4 & \\
\hline & With modified V-shaped cable pattern & 1.122 & 1.140 & 1.6 & \\
\hline
\end{tabular}

Bending moment caused by cable force is in the opposite direction of bending moment due to uniform distributed loading. As presented in Table 3, maximum deflection of the beam along with pre-stressed cable is less than that of the beam without cable. Moreover, maximum deflection is less than allowable limit in simply supported beam. Therefore, using the cable with different patterns satisfies the deflection criterion under service load. Also, maximum deflection values are less in the simply supported and fixed supported beams along with the modified $\mathrm{V}$-shaped pattern of cable, compared to those of the $\mathrm{V}$-shaped pattern of cable. Therefore, considering the obtained results, the modified V-shaped pattern of cable is reckoned as more appropriate one.

\section{The effects of horizontal cable length on the maximum deflection of simply supported and fixed supported beams along with the modified V-shaped pattern of cable}

Eqs. (30) and (37) are considered to calculate maximum deflections of simply supported and fixed supported beams along with the modified V-shaped pattern of cable according to Table 1 for simply supported and fixed supported, Table 2 for cross-section of steel cable, and $l_{b}-2 a$ of Figures 3 and 5 for different values of the length of horizontal cable. Figures 10 and 11 depict the curves of maximum deflection for simply supported and fixed supported beams along with the modified V-shaped pattern of cable for various lengths of horizontal cable.

According to Figures 10 and 11, if the horizontal cable length is zero in the simply supported as well as fixed supported beams along with the modified Vshaped pattern of cable, their maximum deflections are $4.851 \mathrm{~cm}$ and $1.258 \mathrm{~cm}$, respectively. These

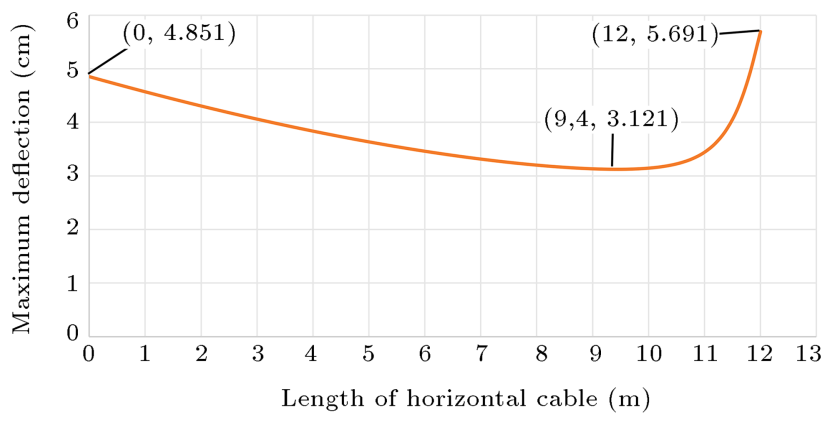

Figure 10. Maximum deflection of simply supported beam along with the modified V-shaped pattern of cable for different values of horizontal cable length.

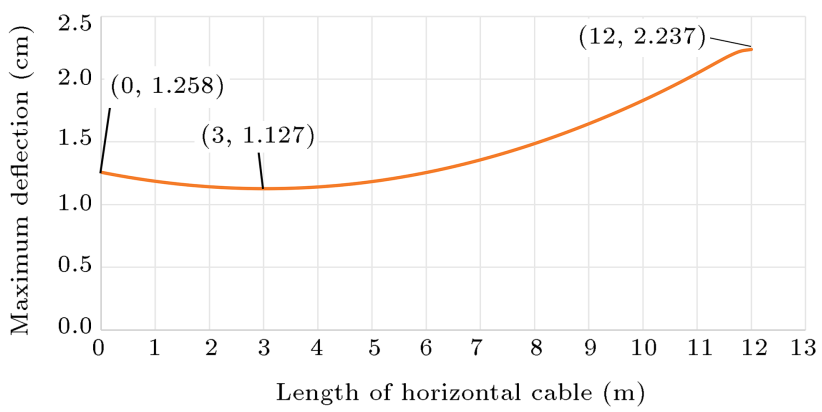

Figure 11. Maximum deflection of fixed supported beam along with the modified $\mathrm{V}$-shaped pattern of cable for different values of horizontal cable length.

values are the results of maximum deflections of simply supported and fixed supported beams along with Vshaped pattern of cable (Table 3 ). Maximum deflection reduces with increasing in the length of horizontal cable. Finally, for horizontal cable lengths of $9.4 \mathrm{~m}$ and $3 \mathrm{~m}$, maximum deflections are minimum; $3.121 \mathrm{~cm}$ and $1.127 \mathrm{~cm}$, respectively, in the simply supported and fixed supported beams along with the modified V-shaped pattern of cable. Since then, maximum 
deflection of the beam augments with increasing in the length of horizontal length. The mentioned values of maximum deflection are $5.691 \mathrm{~cm}$ and $2.237 \mathrm{~cm}$, respectively, when the lengths of horizontal cable and beam are alike. These values are the results of maximum deflection of simply supported and fixed supported beams without cable (Table 3 ). The reason is that for keeping the bending moment in the slope change region of cable continuous, the force of horizontal cable should be equal to the horizontal component of the inclined cable force. Therefore, if the inclined cable becomes vertical in its special status (in the case the length of horizontal cable is equal to that of the beam), the horizontal component of vertical cable force becomes equal to zero; and consequently, the force of horizontal cable becomes zero. As the length of vertical cable which is equal to the distance between two flanges of the beam remains constant, no force is created in the length of cable. Therefore, the cable has no effect on the beam behavior; and the beam deflection is exactly the same as that of the beam without cable.

\section{Comparison of bending moment diagrams of beams without cable and with cable}

The bending moment diagrams of the beams with different support conditions without cable and with different patterns of cable are plotted and compared for the beams presented in Table 1 . The total cross-section areas of steel cables are according to Table 2 and pretensioning stress of steel cables is assumed $600 \mathrm{MPa}$.

\subsection{Comparison of bending moment diagrams of simply supported beams without cable and with cable}

The bending moment diagrams of simply supported beams without cable and with different patterns of cable are plotted based on Eqs. (25), (28), and (29) and are depicted in Figure 12.

As shown in Figure 12, the cable passes through the neutral axis at a distance of $3 \mathrm{~m}$ and $2 \mathrm{~m}$ from each support in simply supported beams with $\mathrm{V}$-shaped and modified $\mathrm{V}$-shaped pattern of cable respectively resulting in the bending moment of the beams to be equal to that of simply supported beam without cable. Moreover, the bending moment of simply supported beam with cable is increased in comparison to the simply supported beam without cable from each support to the place of passing cable through the neutral axis and is decreased between two places of passing cable through the neutral axis. Therefore, it is concluded that if the cable starts from neutral axis at each support, the bending moment of simply supported beam with cable will not increase compared to the simply supported beam without cable.

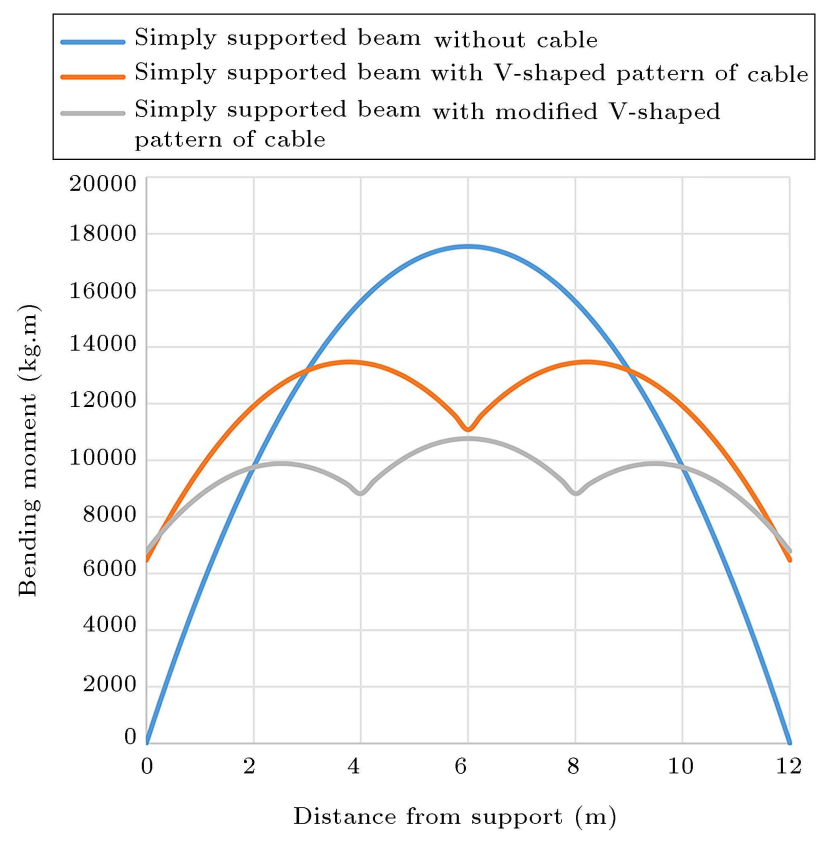

Figure 12. Bending moment diagrams of simply supported beams without cable and with different patterns of cable.

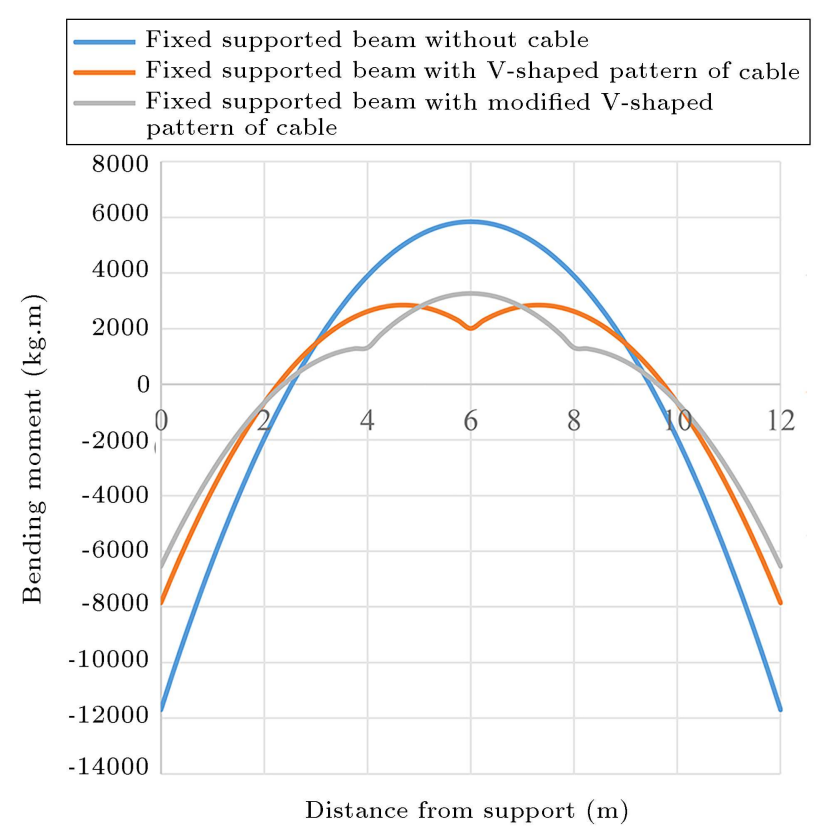

Figure 13. Bending moment diagrams of fixed supported beams without cable and with different patterns of cable.

\subsection{Comparison of bending moment diagrams of fixed supported beams without cable and with cable}

The bending moment diagrams of fixed supported beams without cable and with different patterns of cable are plotted based on Eqs. (31), (35), and (36) and are depicted in Figure 13.

As shown in Figure 13, the bending moment of 
fixed supported beam with cable is decreased compared to that of fixed supported beam without cable from each support to the inflection point of the bending moment of fixed supported beam with cable. Thereafter, the bending moment of fixed supported beam with cable is slightly greater than that of fixed supported beam without cable to the location of the bending moment being equal in fixed supported beams with cable and without cable and then is decreased between two locations of the bending moment being equal in fixed supported beams with cable and without cable.

\section{Sensitivity analysis on the cross-section of steel cable}

In the sensitivity analysis on the cross-section of steel cable, the cross-section of steel cable is considered as 7-wire strand with low relaxation for simply supported and fixed supported beams along with equal numbers of cables at both sides of the webs with the cross section areas of $140 \mathrm{~mm}^{2}$ and $98.71 \mathrm{~mm}^{2}$ for each cable, respectively. These values are considered according to ASTM A416 standard. Constant pre-tensioning has been considered as $600 \mathrm{MPa}$. Tables 4 and 5 present the maximum deflections in the beams with different support conditions and different patterns of cable modeled in Abaqus software for different crosssections of steel cable.
According to the Tables 4 and 5, maximum deflection is reduced in the beams with different support conditions and different patterns of cable with the increase in steel cable cross-section area due to the increase in stiffness in the beam along with cable.

Assuming $140 \mathrm{~mm}^{2}$ for cross-section area of each cable, as observed in Table 4, if the number of steel cables at both sides of beam web increases symmetrically from 1 to 2 and 3 , in each step of increasing the number of steel cables, maximum deflections are reduced by $0.5 \mathrm{~cm}$ and $1 \mathrm{~cm}$ in the simply supported beams along with the V-shaped and modified V-shaped patterns of cable, respectively. Moreover, for cross-section area of steel cable of $280 \mathrm{~mm}^{2}$, maximum deflection values are more and less than allowable deflection, in the simply supported beams with the $\mathrm{V}$-shaped and the modified V-shaped patterns of cable, respectively. Therefore, the cable with $280 \mathrm{~mm}^{2}$ cross-section area cannot satisfy the deflection criterion under service load of simply supported beam along with the Vshaped pattern of cable; however, it can satisfy the case along with the modified V-shaped pattern of cable.

Considering the cables with cross section area of $560 \mathrm{~mm}^{2}$ and $840 \mathrm{~mm}^{2}$, maximum deflection is less than allowable limit in the simply supported beams along with the V-shaped and modified V-shaped patterns of cable. Therefore, these two cross-sections of steel cable can satisfy the deflection criterion.

Table 4. Maximum deflection results of simply supported beams along with different patterns of cable in sensitivity analysis on cross-section area of steel cable.

\begin{tabular}{cccc}
\hline $\begin{array}{c}\text { Total } \\
\text { cross-section } \\
\text { area of steel } \\
\text { cable }\left(\mathbf{m m}^{\mathbf{2}}\right)\end{array}$ & $\begin{array}{c}\text { Maximum } \\
\text { deflection of } \\
\text { simply supported beam } \\
\text { along with the }\end{array}$ & $\begin{array}{c}\text { Maximum } \\
\text { V-shaped cable pattern } \\
\text { deflion of } \\
\text { simply supported } \\
\text { beam along with modified }\end{array}$ & $\begin{array}{c}\text { Allowable } \\
\text { V-shaped cable pattern } \\
\text { dection } \\
(\mathbf{c m})\end{array}$ \\
\hline 280 & 5.387 & 4.817 & \\
560 & 4.898 & 3.768 & 5 \\
840 & 4.411 & 2.728 & 5 \\
\hline
\end{tabular}

Table 5. Maximum deflection of fixed supported beams along with different patterns of cable in sensitivity analysis on cross-section area of steel cable.

\begin{tabular}{|c|c|c|c|}
\hline $\begin{array}{l}\text { Total } \\
\text { cross-section } \\
\text { area of steel } \\
\text { cable }\left(\mathrm{mm}^{2}\right)\end{array}$ & $\begin{array}{c}\text { Maximum } \\
\text { deflection of } \\
\text { fixed supported } \\
\text { beam along with the } \\
\text { V-shaped cable pattern } \\
(\mathrm{cm})\end{array}$ & $\begin{array}{c}\text { Maximum } \\
\text { deflection of } \\
\text { fixed supported beam } \\
\text { along with modified } \\
\text { V-shaped cable pattern } \\
(\mathrm{cm})\end{array}$ & $\begin{array}{l}\text { Allowable } \\
\text { deflection } \\
(\mathrm{cm})\end{array}$ \\
\hline 197 & 1.817 & 1.75 & 5 \\
\hline 395 & 1.253 & 1.122 & 5 \\
\hline 592 & 0.701 & 0.5 & 5 \\
\hline
\end{tabular}


As shown in Table 5, when the cross-section areas of steel cables with the numbers of 1,2 and 3 of $98.71 \mathrm{~mm}^{2}$ increase at both sides of the beam web, in each step of increasing in cross-section areas of steel cables, maximum deflection is reduced by $0.6 \mathrm{~cm}$ in the fixed supported beams along with the $\mathrm{V}$-shaped and modified V-shaped patterns of cable.

\section{Sensitivity analysis on the pre-tensioning stress of the steel cable}

In sensitivity analysis on pre-tensioning of steel cable, the cross-section of steel cable is considered as 7-wire strand with low relaxation for simply supported and fixed supported beams along with equal number of cables at both sides of the webs with the cross section areas of $140 \mathrm{~mm}^{2}$ and $98.71 \mathrm{~mm}^{2}$ for each cable, respectively. These values are considered according to ASTM A416 standard and presented in Table 6.

Table 7 presents the values of maximum deflection of the beams with different support conditions and various patterns of cable modeled in Abaqus software, for different values of pre-tensioning of steel cable.

According to Table 7, maximum deflection is reduced in the beams with different support conditions and different patterns, with increasing in the pretensioning of steel cable due to the increase in bending moment caused by cable force, compared to that resulted from uniform distributed loading.

Based on the Table 7, if the pre-tensioning of the steel cable increases by $200 \mathrm{MPa}$, maximum deflection is reduced by $0.5 \mathrm{~cm}$ and $1 \mathrm{~cm}$ in the simply supported beams along with the V-shaped and modified V-shaped patterns of cable, respectively. Moreover, different values of pre-tensioning stress of steel cable satisfy the deflection criterion in the simply supported beams along with different patterns of cable.

If pre-tensioning of steel cable increases by $200 \mathrm{MPa}$, maximum deflection is reduced by $0.4 \mathrm{~cm}$ in the fixed supported beams along with the $\mathrm{V}$-shaped and modified V-shaped patterns of cable. Moreover, the considered fixed supported beam satisfies the deflection criterion. Therefore, as observed in Table 7 , various values of pre-tensioning of steel cable also satisfy the deflection criterion in the fixed supported beams along with different patterns of cable.

\section{Conclusion}

Cables, due to their low weights, small cross sections, and high tensile strengths, are reckoned as proper alternatives for pre-tensioning long steel beams subjected to uniform distributed loads. In this research, cables are employed to pre-stress the beams with different support conditions in which the deflections are not within the allowable range, despite appropriate design under bending and shear. Theoretical equations have been derived to calculate the increase in pre-tensioning force of the cable, the deflection of simply supported and fixed supported beams with and without cable and required cross-sectional area of steel cable to reach the allowable deflection in steel beams with different support conditions and different patterns of cable. The results are obtained from finite element models and theoretical equations of beams with different support conditions along with cable under uniform distributed loads. They are briefly summarized as follows:

1. The moment at fixed end in fixed supported beam with the V-shaped pattern of cable is equal to

Table 6. Cross-section area of steel cable for beams with different support conditions in sensitivity analysis on the pre-tensioning stress.

\begin{tabular}{ccc}
\hline Type of beam & Simply supported beam & Fixed supported beam \\
\hline Total cross-section area of steel cable $\left(\mathrm{mm}^{2}\right)$ & 840 & 395 \\
\hline
\end{tabular}

Table 7. Maximum deflection results of beams with different support conditions and different cable patterns in sensitivity analysis on the cable pre-tensioning stress.

\begin{tabular}{|c|c|c|c|c|c|}
\hline & \multirow{2}{*}{ Type of beam } & \multicolumn{3}{|c|}{$\begin{array}{c}\text { Cable pre-tensioning } \\
\text { stress (MPa) }\end{array}$} & \multirow[t]{2}{*}{$\begin{array}{c}\text { Allowable } \\
\text { deflection } \\
\qquad(\mathrm{cm})\end{array}$} \\
\hline & & 400 & 600 & 800 & \\
\hline \multirow{2}{*}{$\begin{array}{l}\text { Simply supported } \\
\text { beam }\end{array}$} & Along with the V-shaped pattern & 4.881 & 4.411 & 3.943 & \multirow{2}{*}{5} \\
\hline & Along with the modified V-shaped cable pattern & 3.689 & 2.728 & 1.768 & \\
\hline \multirow{2}{*}{$\begin{array}{l}\text { Fixed supported } \\
\text { beam }\end{array}$} & Along with the V-shaped cable pattern & 1.606 & 1.253 & 0.902 & \multirow{2}{*}{5} \\
\hline & Along with the modified V-shaped cable pattern & 1.511 & 1.122 & 0.732 & \\
\hline
\end{tabular}


the moment at fixed end in the beam without cable $\left(\frac{q l_{b}^{2}}{12}\right)$ but in the fixed supported beam along with the modified V-shaped pattern of cable, the moment at fixed end depends on external loading and total force of the cable as well;

2. Comparing the results obtained from theoretical equations and those of finite element models demonstrates that the theoretical equations developed in this article can properly predict the deflection of simply supported and fixed supported beams without cable and along with different patterns of cable;

3. Adding cable to the beam results in reducing the deflection of beams with different support conditions and different patterns of cable;

4. The deflection is less in the simply supported and fixed supported beams along with the modified Vshaped pattern of cable, compared to that of $\mathrm{V}$ shaped pattern. Therefore, modified V-shaped pattern of cable is recommended as more appropriate one;

5. The effects of horizontal cable on the maximum deflection of simply supported and fixed supported beams along with the modified $\mathrm{V}$-shaped pattern of cable have been studied. According to the obtained results, if the length of horizontal cable is equal to zero, the maximum deflection of beam along with the $\mathrm{V}$-shaped pattern of cable would be obtained. If the length of horizontal cable increases, maximum deflection decreases; and finally, certain length of horizontal cable results in minimum deflection in the simply supported and fixed supported beams along with the modified V-shaped pattern of cable. By increasing in the length of horizontal cable, maximum deflection increases as well. When the lengths of horizontal cable and beam are equal, the deflection results of simply supported and fixed supported beams without cable are obtained;

6. Based on the bending moment diagrams obtained for simply supported beams without cable and with cable, it is concluded that if the cable starts from neutral axis at each support, the bending moment of simply supported beam with cable will not increase compared to the simply supported beam without cable;

7. In beams with different support conditions and different patterns of cable, the deflection is reduced by increasing in the cross-section of steel cable, considering equal pre-tensioning. Moreover, proper values of steel cable cross-sections are obtained, as per which the deflection criterion under service load of beams with different support conditions and different patterns of cable is satisfied;
8. By increasing in pre-tensioning stress in the steel cables of equal cross-sections, the deflection is reduced in the beams with different support conditions and different patterns of cable. Moreover, proper values of pre-tensioning stress are obtained for steel cables, as per which the deflection criterion under service load of beams with different support conditions and different patterns of cable is satisfied.

\section{References}

1. Razavi, M. and Sheidaii, M.R. "Seismic performance of cable zipper-braced frames", Journal of Constructional Steel Research, 74, pp. 49-57 (2012).

2. Hou, X. and Tagawa, H. "Displacement-restraint bracing for seismic retrofit of steel moment frames", Journal of Constructional Steel Research, 65, pp. 10961104 (2009).

3. Fanaie, N., Aghajani, S., and Afsar Dizaj, E. "Theoretical assessment of the behavior of cable bracing system with central steel cylinder", Advances in Structural Engineering, 19(3), pp. 463-472 (2016).

4. Fanaie, N., Aghajani, S., and Afsar Dizaj, E. "Strengthening of moment-resisting frame using cablecylinder bracing", Advances in Structural Engineering, 19(11), pp. 1-19 (2016).

5. Giaccu, G.F. "An equivalent frequency approach for determining non-linear effects on pre-tensioned-cable cross-braced structures", Journal of Sound and Vibration, 422, pp. 62-78 (2018).

6. Brunesi, E., Bolognini, D., and Nascimbene, R. "Evaluation of the shear capacity of precast-prestressed hollow core slabs: numerical and experimental comparisons", Materials and Structures, 48(5), pp. 1503-1521 (2015).

7. Al-Negheimish, A.I., El-Sayed, A.K., Khanbari, M.O., and Alhozaimy, A.M. "Long-term deflection of prestressed SCC hollow core slabs", Construction and Building Materials, 189, pp. 181-191 (2018).

8. Troitsky, M.S. "Prestressed steel bridges-Theory and design", Van Nostrand Reinhold, New York (1990).

9. Le, T.D., Pham, T.M., Hao, H., et al. "Flexural behaviour of precast segmental concrete beams internally prestressed with unbonded CFRP tendons under fourpoint loading", Engineering Structures, 168, pp. 371383 (2018).

10. Pisani, M.A. "Behaviour under long-term loading of externally prestressed concrete beams", Engineering Structures, 160, pp. 24-33 (2018).

11. Lou, T., Lopes, S.M.R., and Lopes, A.V. "Effect of linear transformation on nonlinear behavior of continuous prestressed beams with external FRP cables", Engineering Structures, 147, pp. 410-424 (2017). 
12. Ayyub, B.M., Sohn, Y.G., and Saadatmanesh, H. "Prestressed composite girders under positive moment", Journal of Structural Engineering, 116(11), pp. 2931-2951 (1990).

13. Ayyub, B.M., Sohn, Y.G., and Saadatmanesh, H. "Prestressed composite girders. II: Analytical study for negative moment", Journal of Structural Engineering, 118(10), pp. 2763-2782 (1992).

14. Nie, J.G., Cai, C.S., Zhou, T.R., et al. "Experimental and analytical study of prestressed steel-concrete composite beams considering slip effect", Journal of Structural Engineering, 133(4), pp. 530-540 (2007).

15. Zhou, H., Li, Sh., Chen, L., and Zhang, Ch. "Fire tests on composite steel-concrete beams prestressed with external tendons", Journal of Constructional Steel Research, 143, pp. 62-71 (2018).

16. Belletti, B. and Gasperi, A. "Behavior of prestressed steel beams", Journal of Structural Engineering, 136(9), pp. 1131-1139 (2010).

17. Park, S., Kim, T., Kim, K., and Hong, S. "Flexural behavior of steel I-beam prestressed with externally unbonded tendons", Journal of Constructional Steel Research, 66, pp. 125-132 (2010).

18. Kambal, M., Elhaj, M., and Jia, Y. "Theoretical and experimental study on flexural behavior of prestressed steel plate girders", Journal of Constructional Steel Research, 142, pp. 5-16 (2018).

19. Zhang, W. "Symmetric and antisymmetric lateraltorsional buckling of prestressed steel I-beams", ThinWalled Structures, 122, pp. 463-479 (2018).

20. Thai, S., Kim, N., Lee, J., and Kang, J.W. "Optimum design of cable nets by using genetic algorithm", International Journal of Steel Structures, 17(3), pp. 1183-1198 (2017).

21. Hoadley, P.G. "Behavior of prestressed composite steel beams", Journal of the Structural Division, ASCE, $\mathbf{8 9}$, pp. 21-34 (1966).

22. Belenya, E.I., Prestressed Load-Bearing Metal Structures, Russian Edition, Moscow (1977).

23. American Institute of Steel Construction (AISC) ANSI/AISC360-10, Specification for structural steel buildings, Chicago, IL (2010).
24. American Society for Testing and Materials (ASTM), Standard Specification for Low-Relaxation, Seven-Wire Steel Strand for Prestressed Concrete (ASTM A416M), Philadelphia, Pa (2018).

\section{Biographies}

Nader Fanaie obtained his BS, MS and $\mathrm{PhD}$ degrees in Civil Engineering from the Department of Civil Engineering at Sharif University of Technology, Tehran, Iran. He graduated in 2008 and, at present, is a faculty member of $\mathrm{K}$. N. Toosi University of Technology, Tehran, Iran. He has supervised 30 MS theses up to now. His field of research includes seismic hazard analysis, earthquake simulation, seismic design and IDA. He has published 40 journal and conference papers, and also 10 books. He received 3rd place in the first mathematical competition, held at Sharif University of Technology, in 1996, and a Gold Medal in "The 4th Iranian Civil Engineering Scientific Olympiad" in 1999. In 2001, he achieved the first rank in the exam of $\mathrm{PhD}$ scholarship abroad. He has also been acknowledged as an Innovative Engineer on 'Engineering Day', in 2008.

Fatemeh Partovi received her BS and MS degrees in Civil engineering from the Department of Civil Engineering at K. N. Toosi University of Technology, Tehran, Iran. She graduated in 2017. She achieved 4th and 2nd ranks in her undergraduate and graduate classes, respectively. She has published multiple papers in journals of Central South University, Scientia Iranica, and Constructional Steel Research.

Shervin Safaei Faegh was born in Tehran, Iran, in 1991. He received his BSc degree in structural engineering from Islamic Azad University Central Branch and MSc degree from K. N. Toosi University of Technology in Tehran. His research interests include steel structures, steel connections, energy dissipative devices, concrete and steel plate shear walls, and non-linear finite element simulation via Abaqus software. 